\title{
Pharmacological and Genetic Reversal of Age-Dependent Cognitive Deficits Attributable to Decreased presenilin Function
}

\author{
Sean M. J. McBride, ${ }^{1,2 *}$ Catherine H. Choi, ${ }^{1,2,3 *}$ Brian P. Schoenfeld, ${ }^{1,2 *}$ Aaron J. Bell, ${ }^{1,2}$ David A. Liebelt, ${ }^{1,2}$ \\ David Ferreiro, ${ }^{1,2}$ Richard J. Choi, ${ }^{1,2}$ Paul Hinchey, ${ }^{1,2}$ Maria Kollaros, ${ }^{1,2}$ Allison M. Terlizzi, ${ }^{1,2}$ Neal J. Ferrick, ${ }^{1,2}$ \\ Eric Koenigsberg, ${ }^{1,2}$ Rebecca L. Rudominer, ${ }^{1,2}$ Ai Sumida, ${ }^{4}$ Stephanie Chiorean, ${ }^{4}$ Kathleen K. Siwicki, ${ }^{5}$ \\ Hanh T. Nguyen, ${ }^{1,2}$ Mark E. Fortini, ${ }^{6}$ Thomas V. McDonald, ${ }^{1,2}{ }^{\dagger}$ and Thomas A. Jongen ${ }^{4 \dagger}$ \\ ${ }^{1}$ Section of Molecular Cardiology and ${ }^{2}$ Departments of Medicine and Molecular Pharmacology, Albert Einstein College of Medicine, Bronx, New York \\ 10461, ${ }^{3}$ Department of Dermatology, Drexel University College of Medicine, Philadelphia, Pennsylvania 19102, ${ }^{4}$ Department of Genetics, University of \\ Pennsylvania School of Medicine, Philadelphia, Pennsylvania 19104, ${ }^{5}$ Department of Biology, Swarthmore College, Swarthmore, Pennsylvania 19081, \\ and ${ }^{6}$ Department of Biochemistry and Molecular Biology, Thomas Jefferson University, Philadelphia, Pennsylvania 19107
}

\begin{abstract}
Alzheimer's disease (AD) is the leading cause of cognitive loss and neurodegeneration in the developed world. Although its genetic and environmental causes are not generally known, familial forms of the disease (FAD) are attributable to mutations in a single copy of the Presenilin $(P S)$ and amyloid precursor protein genes. The dominant inheritance pattern of FAD indicates that it may be attributable to gain or change of function mutations. Studies of FAD-linked forms of presenilin ( $p s n)$ in model organisms, however, indicate that they are loss of function, leading to the possibility that a reduction in $P S$ activity might contribute to FAD and that proper $p s n$ levels are important for maintaining normal cognition throughout life. To explore this issue further, we have tested the effect of reducing $p s n$ activity during aging in Drosophila melanogaster males. We have found that flies in which the dosage of $p s n$ function is reduced by 50\% display age-onset impairments in learning and memory. Treatment with metabotropic glutamate receptor (mGluR) antagonists or lithium during the aging process prevented the onset of these deficits, and treatment of aged flies reversed the age-dependent deficits. Genetic reduction of Drosophila metabotropic glutamate receptor $(D m G l u R A)$, the inositol trisphosphate receptor $\left(\operatorname{Ins} \mathrm{P}_{3} \mathrm{R}\right)$, or inositol polyphosphate 1-phosphatase also prevented these age-onset cognitive deficits. These findings suggest that reduced $p s n$ activity may contribute to the age-onset cognitive loss observed with FAD. They also indicate that enhanced mGluR signaling and calcium release regulated by $\mathrm{InsP}_{3} \mathrm{R}$ as underlying causes of the age-dependent cognitive phenotypes observed when $p s n$ activity is reduced.
\end{abstract}

\section{Introduction}

Alzheimer's disease $(\mathrm{AD})$ is a neurodegenerative disease characterized by progressive impairments in memory and cognitive

Received Feb. 25, 2010; revised March 31, 2010; accepted June 1, 2010.

This work was supported by the FRAXA Research Foundation (S.M.J.M., C.H.C., T.A.J.), National Institutes of Health (NIH) Grants NS046573 (T.A.J.), GM087650 (M.E.F.), and AG14583 (M.E.F.), an Alzheimer's Disease Center pilot award from NIH Grant AG-10124 (T.A.J.), and an Alzheimer's Disease Research pilot award, a program of the American Health Assistance Foundation (T.A.J.). T.V.M. and S.M.J.M. were supported by Autism Speaks, and E.K. was supported by The National Fragile X Foundation. The Albert Einstein College of Medicine MSTP grant funded S.M.J.M. We thank Evan Braunstein, Joseph Hinchey, Sean Campbell, Suzanne Zukin, Peter Davies, Myles Akabas, Nancy Carasco, Lloyd Fricker, Kami Kim, Matt Tremblay, Mike Gertner, Kevin Foskett, and Goran Periz for critical comments during this project. We thank Oliver Schipper for help with fly husbandry. We acknowledge Mel Feany, Gaiti Hasan, and Charles Zuker for reagents.

*S.M.J.M., C.H.C., and B.P.S. contributed equally to this work.

${ }^{\dagger}$ T.V.M. and T.A.J. contributed equally to this work.

Correspondence should be addressed to any of the following: Sean M. J. McBride, c/o Thomas McDonald Lab, Section of Molecular Cardiology and Department of Molecular Pharmacology, Albert Einstein College of Medicine, Forchheimer G35, 1300 Morris Park Avenue, Bronx, NY 10461, E-mail: smcbride@aecom.yu.edu; Thomas McDonald, Section of Molecular Cardiology and Department of Molecular Pharmacology, Albert Einstein College of Medicine, Forchheimer G35, 1300 Morris Park Avenue, Bronx, NY 10461, E-mail: mcdonald@aecom.yu.edu; or Thomas A. Jongens, Department of Genetics, University of Pennsylvania, School of Medicine, 538A CRB, 415 Curie Boulevard, Philadelphia, PA 19104, E-mail: jongens@mail.med.upenn.edu.

D0I:10.1523/JNEUROSCI.1017-10.2010

Copyright $\odot 2010$ the authors $\quad 0270-6474 / 10 / 309510-13 \$ 15.00 / 0$ abilities with a typical late age onset, although in cases of early onset familial Alzheimer's disease (FAD), the onset can be as early as the third decade of life. The histopathological hallmarks of $\mathrm{AD}$ are amyloid plaques and neurofibrillary tangles in the brains of afflicted patients (Alzheimer, 1907; Selkoe, 2002; Mattson, 2004; Hardy, 2006; Small and Gandy, 2006). The majority of FAD cases are linked to mutations in the Presenilin 1 and Presenilin 2 (PS1/ $P S 2)$ genes, with additional cases linked to mutations in the amyloid precursor protein $(A P P)$ gene. FAD cases exhibit dominant inheritance pattern in which the disease is caused by a mutation in a single copy of one of these three genes (Mattson, 2004; Shen and Kelleher, 2007).

In humans as well as in animal and cell culture models of AD, FAD-linked $P S$ and $A P P$ mutations generally, although not in all cases, result in an enhanced ratio of $\beta$-amyloid 1-42 $\left(\mathrm{A} \beta_{1-42}\right)$ to $\mathrm{A} \beta_{1-40}$ (Moehlmann et al., 2002; Schroeter et al., 2003; QiTakahara et al., 2005; Walker et al., 2005; Kumar-Singh et al., 2006; Sambamurti et al., 2006; De Strooper, 2007; Isoo et al., 2007; Shen and Kelleher, 2007; Shioi et al., 2007). This finding and the dominant inheritance pattern of FAD has led to a model suggesting that FAD-linked mutations in PS1, PS2, and APP lead 
to gain-of-function or change-of-function forms of PS or APP protein (Hardy, 2006; Small and Gandy, 2006).

Studies in mice, Drosophila, and Caenorhabditis elegans indicate that FAD-linked presenilin mutations have reduced function with respect to cleavage substrates (De Strooper, 2007; Shen and Kelleher, 2007). Both loss-of-function mutations in presenilin ( $p s n)$ and FAD-linked mutations lead to an increase in GSK-3 $\beta$ activity, which is normally negatively regulated by presenilin and may be a $\gamma$-secretase-independent function (Baki et al., 2004; Serban et al., 2005; Shioi et al., 2007). Finally, the high number of different mutations in presenilin that give rise to $\mathrm{FAD}$ is more consistent with a loss-of-function mechanism as gain-of-function or change-of-function mutations for a protein are normally considered to be rare, particularly because the mutations in presenilin 1 are spread throughout different portions of the protein (Saura et al., 2004; De Strooper, 2007; Shen and Kelleher, 2007). Together, these results suggest the possibility that a reduction in the functional activity of PS1 and PS2 contribute to the pathogenesis of FAD, including cognitive loss.

We investigate the effect of reducing psn function on cognition during aging as an approach to determine whether lowered $p s n$ function (but not completely absent function) may contribute to cognitive impairment. We find that reduction in $p s n$ function leads to age-onset cognitive deficits. Through pharmacological and genetic studies, we identify misregulation of metabotropic glutamate receptor (mGluR) signaling and inositol trisphosphate receptor $\left(\mathrm{InsP}_{3} \mathrm{R}\right)$-mediated calcium release, as causal for the observed ageonset cognitive dysfunction. The implications of these studies toward understanding and possibly treating certain aspects of $\mathrm{AD}$ are discussed.

\section{Materials and Methods}

Drosophila strains and drug testing. Drosophila strains used in this study are described in supplemental Table 1 (available at www.jneurosci.org as supplemental material). The Drosophila strains were cultured as in the study by McBride et al. (2005). Drugs were obtained from Tocris Cookson and solubilized according to the instructions of the manufacturer. They were added to the fly food after cooling to the appropriate concentration. Concentrations used were based on dose-response testing performed in a previous study on the Drosophila fragile X mental retardation gene dfmrl mutants (McBride et al., 2005). Vehicle for each drug was added to the appropriate control food for each experiment.

Behavioral training and testing. Virgin male flies were collected under ether anesthesia within $4 \mathrm{~h}$ of eclosion. Virgin XX, yf females were collected on the day of eclosion and kept in food vials in groups of 10-15. Flies were aged in a $12 \mathrm{~h}$ light/dark cycle before behavioral training and testing. All testing was performed during the relative light phase. Mated females were $5 \mathrm{~d}$ old and observed to mate with a male the night before training. The virgin females that were used as targets were $4 \mathrm{~d}$ old. All male subjects were transferred to fresh control food the day before testing. Male flies were assigned to random groups for behavior training and testing, which was performed blind (Siegel and Hall, 1979; Kane et al., 1997; McBride et al., 1999). The total amount of time a male was engaged in courtship activity while paired with an unanesthetized target female during a test period of $10 \mathrm{~min}$ or until successful copulation occurred was scored. A courtship index (CI) was calculated as the percentage of total observation time spent courting (Siegel and Hall, 1979). Binning of naive courtship behavior was performed as in the study by McBride et al. (2005), except that the percentage of flies advancing to a particular stage of courtship during the courtship interval was scored and compiled. Locomotor testing was done as in the study by McBride et al. (2005).

Cell death and mushroom body morphological analysis. Terminal deoxynucleotidyl transferase-mediated biotinylated UTP nick end labeling (TUNEL) assays were performed according to Ye and Fortini (1999) using a S7110 kit from Oncor. Brains were treated following the protocol for imaginal discs. Acridine Orange stainings were performed according to Hériché et al. (2003). Analysis of stained brains was performed by three-dimensional reconstruction of optic stacks taken at $0.5 \mu \mathrm{m}$ using a Leica scanning confocal microscope. The number of cell death foci and their relative position were tabulated for each genotype. Analysis of mushroom body (MB) morphology was performed as described by McBride et al. (2005).

Statistical analyses. CIs of tested males were subjected to arcsin square root transformations to approximate normal distributions (Joiner and Griffith, 1997; McBride et al., 1999). ANOVAs were performed on pairwise comparisons of arcsin transformed data to get critical $p$ values. All statistics were performed using Statview 3.0.

\section{Results}

\section{Examination of the effect of decreased presenilin activity during aging}

Drosophila has a single $p s n$ gene ortholog, the protein sequence of which is $~ 50 \%$ identical to human PS1 and PS2 (Boulianne et al., 1997; Hong and Koo, 1997). The encoded presenilin protein is expressed in a wide range of tissues, including the brain (Ye and Fortini, 1998). Isolation and characterization of several loss-offunction mutants have revealed that $p s n$ is an essential gene, required for proper neurogenesis and Notch processing (Struhl and Greenwald, 1999; Ye et al., 1999). Biochemical studies of the Drosophila presenilin protein have shown that it is a component of the $\gamma$-secretase complex like its mammalian counterparts (De Strooper, 2003; Hu and Fortini, 2003; Takasugi et al., 2003).

The underlying nature of the mutations in PS1 and PS2 that give rise to FAD are unclear (Saura et al., 2004; Qi-Takahara et al., 2005; Walker et al., 2005; Kumar-Singh et al., 2006; Sambamurti et al., 2006; De Strooper, 2007; Hardy, 2007; Isoo et al., 2007; Shen and Kelleher, 2007; Wolfe, 2007). However, studies in model organisms indicate that the FAD-linked mutations may result in a reduction of PS1 and PS2 activity (De Strooper, 2007; Shen and Kelleher, 2007). This possibility suggests that some phenotypes associated with Alzheimer's disease, including age-onset cognitive loss, may be attributable to a reduction in overall PS activity levels. To investigate this possibility further, we tested the effect of reducing psn activity using known psn loss-of-function alleles. We evaluated the learning and memory capabilities of young adult flies heterozygous for a given $p s n$ mutant allele (hereafter referred to as "psn-het flies"), with only 50\% of the psn found in wild-type (WT) control flies [the wild-type control strain is Oregon-R (OreR), the background strain from which the $p s n$ alleles we used in this study were derived)]. We then reevaluated their capabilities at an older age to determine whether any age-related cognitive decline could be observed. We took advantage of the large number of $p s n$ alleles with diminished function that have been obtained from several genetic screens. In total, 10 different loss-of-function alleles of $p s n$ were examined, to ensure that any observed effects were not attributable to second site mutations or other background effects and crossed each to our WT OreR line (for a description of the alleles used, see Materials and Methods and Supplemental Table 1, available at www. jneurosci.org as supplemental material).

\section{Examining naive courtship, learning, and memory in aged control flies}

Before embarking on an examination of the effects of aging on psn-het flies, using the courtship based assays, we first needed to establish a timeline in which courtship-based learning and memory were not affected in our control OreR (WT) flies. The effect of aging on naive courtship and courtship conditioned learning and memory has not been extensively characterized. The lifespan of Drosophila is $\sim 60 \mathrm{~d}$ (after eclosion, in adult form); therefore, a 

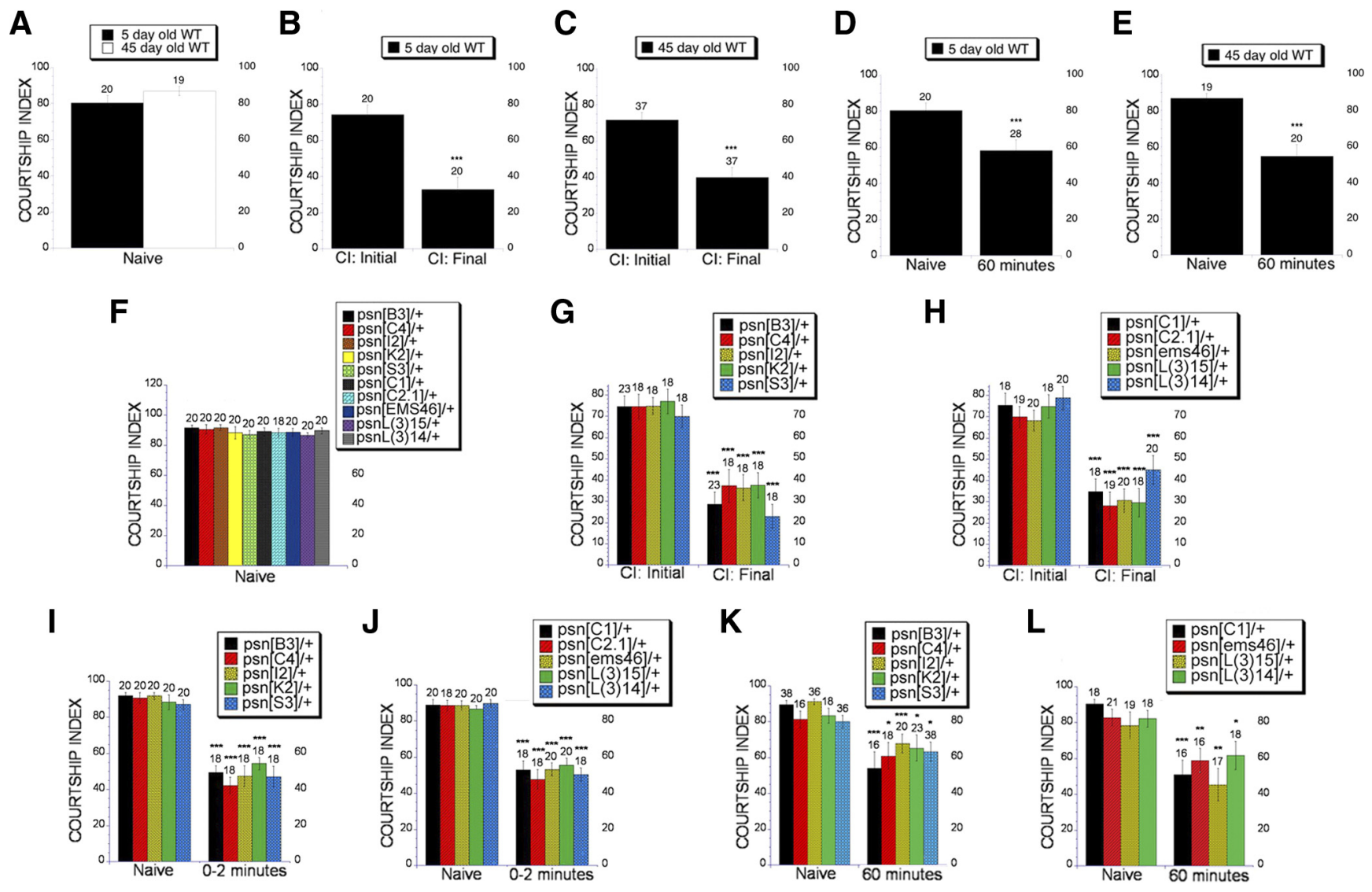

Figure 1. The behavior of young adult (5-d-old) and elderly adult (45-d-old) wild-type flies (OreR). $\boldsymbol{A}$-E, Naive courtship, learning during training, and short-term memory were examined in WT flies at 5 and $45 \mathrm{~d}$ of age. Mean \pm SEM Cls are plotted; $n$ values are indicated above each bar for all groups. The levels of significance are indicated $\left({ }^{*} p<0.05,{ }^{* *} p<0.01,{ }^{* * *} p<0.001\right)$. WT flies are OreR. $\boldsymbol{A}$, Naive courtship in 5-d-old WT (black bar) and 45-d-old WT (open bar) flies. $\boldsymbol{B}$, Learning during training in 5-d-old WT flies. $\boldsymbol{C}$, Learning during training in 45 -d-old WT flies. $\boldsymbol{D}$, Short-term memory in 5-d-old WT flies. $E$, Short-term memory in 45-d-old WT flies. Thus, at $45 \mathrm{~d}$ of age, there is no significant change in naive courtship behavior or cognition in WT flies. The behavior of young adult (5-d-old) psn-het flies. $F$ - $L$, Naive courtship, learning during training, immediate recall, and short-term memory were examined in psn-het flies at $5 \mathrm{~d}$ of age. Psn-het males for the $p s n$ alleles psn B3, psn (4, psn 12, psn K2, psn S3, psn C1, psn C2.1, psn EMS46, psn L(3) 15, and psn L(3) 14 were aged for 5 d after eclosion. psn-het males were tested for naive courtship (F), learning during training $(\boldsymbol{G}, \boldsymbol{H})$, immediate recall $(0-2$ min after training) $(\boldsymbol{I}, \boldsymbol{J})$, and short-term memory ( 60 min after training) $(\boldsymbol{K}, \boldsymbol{L})$. No deficits in behavior or cognitive capabilities were detected in any of the tests performed on the young adult $p s n$-het flies.

5-d-old adult fly is relatively "young," a 30-d-old fly is "moderately aged," and a 45-d-old fly is relatively "old."

Courting Drosophila males perform a characteristic sequence of behaviors when paired with a female: orienting toward and following the female, tapping her with his forelegs, vibrating one wing, licking her genitalia, and attempting to copulate (Hall, 1994). The percentage of time the male spends performing any of these behaviors toward a target during a defined period of time is referred to as the CI (Siegel and Hall, 1979). We tested progressively older naive males and found that 45-d-old WT flies perform naive courtship as robustly as young 5-d-old flies (Fig. 1A). This indicates that there are no sensory impairments with age that diminish courtship. Furthermore, the quality of this courtship was not different between 5- and 45-d-old WT flies (supplemental Fig. S1, available at www.jneurosci.org as supplemental material), nor was the level of locomotor activity (supplemental Fig. S2, available at www.jneurosci.org as supplemental material).

We next determined an age range within which learning and memory would be intact in WT flies. Learning and memory can be examined in Drosophila by assaying conditioned courtship behavior. In conditioned courtship, a male fly learns to modify his courtship behavior after experience with an unreceptive female (Siegel and Hall, 1979; Hall, 1994). Virgin females generally respond to a courting male by mating. However, recently mated females are unreceptive and have an overlapping but altered pheromonal profile that naive males find less provocative than that of virgin female targets (Ejima et al., 2007). A naive male paired with a mated female will initially court her, but his courtship activity soon decreases. When this learning during training (LDT) is quantified, by comparing the CI during the first $10 \mathrm{~min}$ with a mated female to the CI of the last $10 \mathrm{~min}$ period of a $1 \mathrm{~h}$ pairing, wild-type flies typically show a $\geq 40 \%$ decrease in courtship activity (Joiner and Griffith, 1997; Kane et al., 1997). Hence, LDT is a form of behavioral plasticity but is distinct and separate from courtship suppression assayed after training, which is a form of associative memory (Tompkins et al., 1983; Ackerman and Siegel, 1986). When a male is paired with a virgin female after $1 \mathrm{~h}$ of experience with a mated female, his courtship remains depressed for 2-3 h (Siegel and Hall, 1979). This effect is not a general suppression of all courtship activity, because trained males do not modify their courtship of other pheromonally distinct targets (Ejima et al., 2005; Siwicki et al., 2005). After training with a mated female, memory is measured as a decrease in CI toward virgin females in trained males relative to naive controls.

In Drosophila, five phases of memory have been elucidated by a combination of genetic and pharmacological dissection. There is an immediate recall memory (immediate memory) at $0-2$ min after training, short-term memory out to $1 \mathrm{~h}$, medium-term 

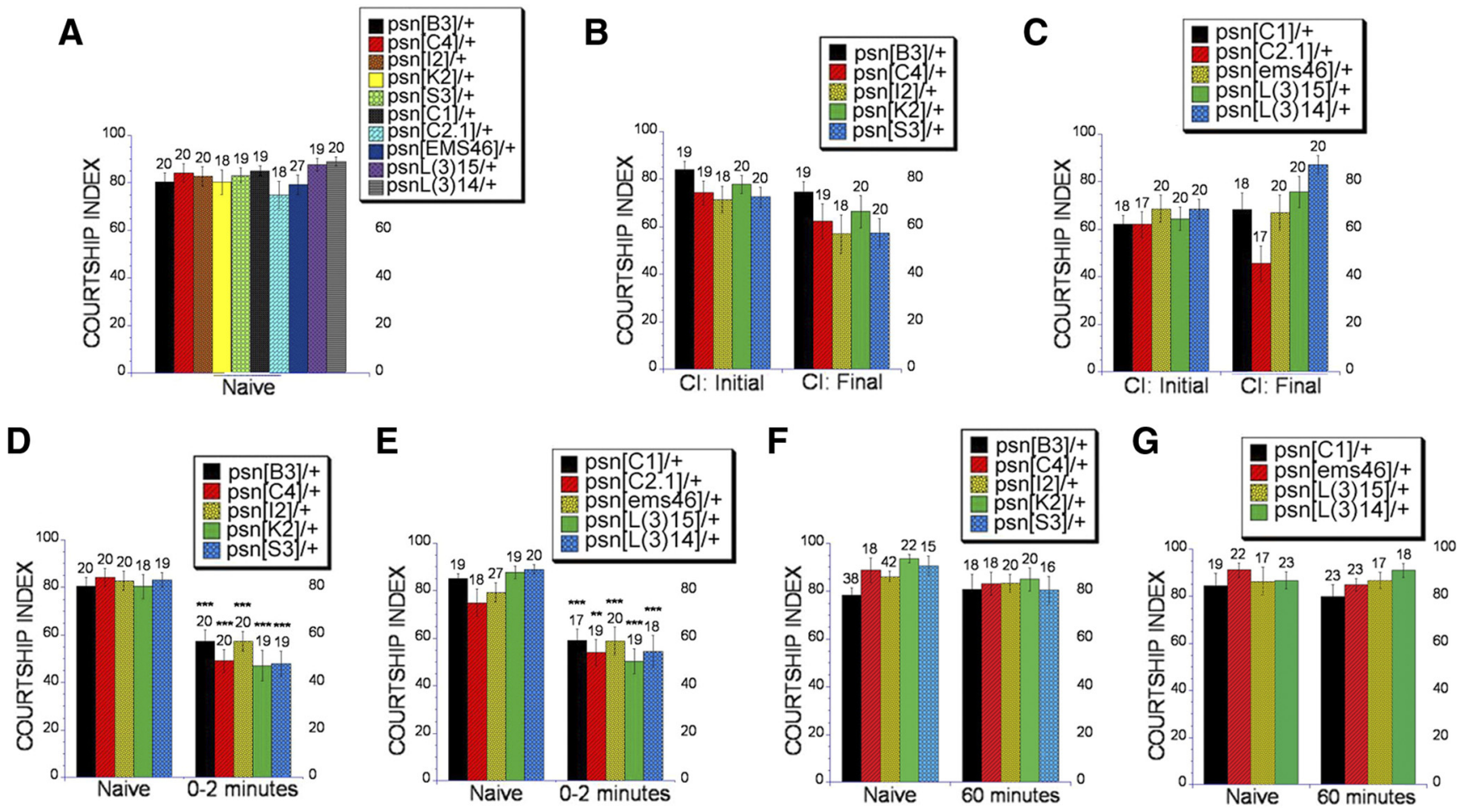

Figure 2. Naive courtship, LDT, immediate recall, and short-term memory in 30-d-old (late middle aged) psn-het flies. psn-het males for the psn alleles psn B3, psn C4, psn I2, psn K2, psn S3, psn C1, psn C2.1, psn EMS46, psn L(3)15, and psn L(3)14 were aged for $30 \mathrm{~d}$ after eclosion. Mean \pm SEM Cls are plotted. $n$ values are indicated above each bar for all groups. The levels of significance are indicated ${ }^{* *} p<0.01,{ }^{* * *} p<0.001$ ). A, Naive courtship levels remained robust and only slightly reduced from 5-d-old psn-het flies (compare with Fig. $1 F$ ) in all psn-het males. B, C, psn-het males were tested for learning during training, and none of the $p s n$-het males demonstrated at least a $40 \%$ reduction in courtship activity during the training session or a statistically significant reduction in courtship behavior. Therefore, $p s n$-het flies have an age-dependent impairment in learning during training. $\boldsymbol{D}, \boldsymbol{E}$, Immediate recall remained intact in all psn-het males. $\boldsymbol{F}, \mathbf{G}$, psn-hets were also tested for short-term memory at $60 \mathrm{~min}$ after training. All lines failed to exhibit short-term memory, in contrast to their behavior at $5 \mathrm{~d}$ of age (Fig. $1 \mathrm{~K}, \mathrm{~L})$.

memory out to $6 \mathrm{~h}$, anesthesia-resistant memory out to $2 \mathrm{~d}$, and long-term memory lasting up to $9 \mathrm{~d}$ after training that appears to be dependent on protein synthesis (Skoulakis and Grammenoudi, 2006). Intact short-term memory is dependent on intact immediate recall. However, immediate recall and short-term memory are distinct from LDT. Therefore, intact memory can occur without LDT, and learning during training can occur without posttraining memory (Joiner and Griffith, 1997; Kane et al., 1997; McBride et al., 2005).

To assess LDT, a male fly was placed in a training chamber with a previously mated female for $1 \mathrm{~h}$, and the amount of time the male spent courting in the initial 10 min interval was compared with the time spent engaged in courtship in the final $10 \mathrm{~min}$ interval. Normal LDT in 5-d-old WT flies is illustrated by a significant $\geq 40 \%$ decrease in courtship during the training (Fig. $1 \mathrm{~B}$ ), and short-term memory is illustrated in 5-d-old WT flies by a significant decrease in courtship toward virgin females $1 \mathrm{~h}$ after training (Fig. 1D). We found that 45-d-old WT flies also demonstrated intact LDT and short-term memory (Fig. 1C,E). These studies indicate that the courtship-based learning and memory paradigm can be used to study aging-related issues of cognition and behavior in flies.

\section{Naive courtship, LDT, and memory in young and aged adult psn-het flies}

Courtship was robust in naive males of all 10 psn-het genotypes examined as young adults at $5 \mathrm{~d}$ of age (Fig. $1 F$ ). Naive males of these $p s n$-het genotypes also displayed the normal steps of courtship behavior and normal levels of locomotor activity (supplemental Figs. S3, S4, available at www.jneurosci.org as supplemental material).
LDT at $5 \mathrm{~d}$ of age in all $10 \mathrm{psn}$-het genotypes was normal, as evidenced by decreases of $>40 \%$ from initial CI to final CI during training with mated females (Fig. $1 G, H$ ). To examine the immediate recall memory at $5 \mathrm{~d}$ of age, we took males that had just completed a $1 \mathrm{~h}$ training session with a previously mated female and immediately placed them in a new chamber with a virgin target female for a $10 \mathrm{~min}$ courtship assay. This CI was then compared with the courtship level of naive males that had been placed in a training chamber for $1 \mathrm{~h}$ with no female, before being introduced to a virgin target female. Immediate recall was intact in all 10 psn-het genotypes examined (Fig. $1 \mathrm{I}, \mathrm{J}$ ). To assay shortterm memory, the trained male was placed in a holding chamber for $60 \mathrm{~min}$ and then subsequently placed in a testing chamber with a virgin female target. Nine of the $p s n$-het genotypes were tested and found to have normal short-term memory at $5 \mathrm{~d}$ of age (Fig. $1 K, L)$.

We next examined naive courtship and LDT in 30-d-old (late middle age) psn-het males. No significant effect on the level of naive courtship (Fig. 2A), its quality (supplemental Fig. S5, available at www.jneurosci.org as supplemental material), locomotor activity (supplemental Fig. S6, available at www.jneurosci.org as supplemental material), or phototaxis or chemotaxis (data not shown) was observed. However, males of all 10 different $p s n$-het genotypes failed to demonstrate the typical decrease in courtship activity in LDT at $30 \mathrm{~d}$ of age (Fig. $2 \mathrm{~B}, \mathrm{C}$ ). Impaired LDT is a very rare phenotype in Drosophila but has been seen previously in young adult flies that have altered calcium/calmodulindependent kinase II or protein kinase C (PKC) expression or activity (Joiner and Griffith, 1997; Kane et al., 1997). These re- 
sults demonstrate an age-dependent impairment in LDT in psnhet male flies by $30 \mathrm{~d}$ of age.

We next examined immediate recall and short-term memory in the $p s n$-het flies at $30 \mathrm{~d}$ of age. We found that males of all 10 different $p s n$-het genotypes displayed intact immediate recall at $30 \mathrm{~d}$ of age (Fig. 2D,E). Intact immediate recall of courtship memory without intact LDT has been observed previously in young adult Drosophila (Joiner and Griffith, 1997; Kane et al., 1997). Although immediate recall was intact, examination of short-term memory in nine of the heterozygous mutant presenilin lines, at $30 \mathrm{~d}$ of age, revealed that this form of memory was no longer intact (Fig. $2 F, G)$. This is in contrast to 5-d-old psn-het and 45-d-old WT flies, which exhibited intact short-term memory. This demonstrates that there is an age-dependent impairment of short-term memory in heterozygous $p s n$ loss-of-function flies.

\section{Genetic interaction between psn and $d f m r 1$}

In an effort to identify novel pathways affected as a result of the reduction in psn levels, we looked for genetic interactions between $p s n$ and other genes known to affect cognition and behavior that might play a role in presenilin signaling based on the literature. Interestingly, we identified a strong genetic interaction between $p s n$ and the Drosophila fragile $\mathrm{X}$ mental retardation gene $d f m r 1$. At $5 \mathrm{~d}$ of age, $p s n$ and $d f m r 1$ heterozygous single-mutant flies display normal naive courtship levels relative to their given genetic background (supplemental Fig. S7, available at www. jneurosci.org as supplemental material). However, 5-d-old flies that are transheterozygous mutant for both $p s n$ and $d f m r 1$ display a severe reduction in naive courtship levels, which is rescued by the introduction of one wild-type copy of a $d f m r 1$ genomic rescue construct. Such heterozygous synergistic genetic interactions are rare and suggest that both genes act in one or more common pathways important for normal naive courtship activity.

\section{Prevention of age-dependent LDT and short-term memory deficits with pharmacological treatment}

To explore the possibility of pharmacologically rescuing some of the age-dependent $p s n$-het phenotypes and in light of the genetic interaction between $p s n$ and $d f m r 1$ described above, we focused on treatments that rescue naive courtship and cognitive deficits in $d f m r 1$ mutants. One pathway that is known to be affected in both fly and mouse models of fragile $\mathrm{X}$ is $\mathrm{mGluR}$ signaling (Huber et al., 2002; McBride et al., 2005; Yan et al., 2005; Dölen et al., 2007; Bolduc et al., 2008). In previous studies, we found that several of the phenotypes displayed by the $d f m r 1$ mutants, including naive courtship and memory, could be rescued by treatment with antagonists of DmGluRA and $\mathrm{LiCl}$ (McBride et al., 2005). More recent studies have also observed this and have also found that similar rescue is obtained by genetic reduction of DmGluRA activity, the sole Drosophila mGluR (Bolduc et al., 2008; Pan et al., 2008).

Our working model is that treatment of flies with both lithium and antagonists of DmGluRA will increase cAMP signaling and may also decrease $\mathrm{Ins}_{3} \mathrm{R}$-mediated calcium release (Fig. 3A). Lithium inhibits GSK-3 $\beta$ activity by competing with the magnesium-binding site and increasing phosphorylation at serine 9 (Gould and Manji, 2005; Huang and Klein, 2006; Jope and Roh, 2006). There is an antagonistic relationship between protein kinase A (PKA) and GSK-3 $\beta$; therefore, this acts to upregulate the downstream effect of cAMP signaling because GSK-3 $\beta$ can inhibit cAMP response element-binding protein (CREB)-mediated gene transcription (Bullock and Habener,
1998; Grimes and Jope, 2001; Mai et al., 2002; Tanji et al., 2002; Hansen et al., 2004; Gould and Manji, 2005). Lithium also inhibits inositol polyphosphate 1-phosphatase (IPPase) (Acharya et al., 1998) and inositol monophosphatase (IMPase) (Berridge, 1993), thereby reducing the pool of $\mathrm{InsP}_{3}$ available to stimulate $\mathrm{InsP}_{3} \mathrm{R}$-mediated calcium signaling (Berridge, 1993; Takei et al., 1998; Williams et al., 2002). Previous heterologous cell-based studies have shown that DmGluRA can couple to heterotrimeric $\mathrm{G}_{\mathrm{i}}$, leading to decreases in cAMP levels (Parmentier et al., 1996). More recent in vivo studies have shown that DmGluRA also has properties typically found associated with $\mathrm{G}_{\mathrm{q}}$-coupled group I mGluRs such as regulating synaptic morphology and AMPA receptor presentation (Bogdanik et al., 2004; Pan and Broadie, 2007; Pan et al., 2008). Thus, antagonizing DmGluRA activity will increase cAMP levels (by relieving inhibition of cAMP after synaptic stimulation) and will possibly decrease $\mathrm{InsP}_{3} \mathrm{R}$-mediated calcium signaling (Fig. 3A) (McBride et al., 2005). We therefore explored the possibility that the age-dependent cognitive deficits could be rescued by treatment with DmGluRA antagonists as well as lithium.

For this experiment, we used the competitive group II antagonist LY341495 [(2S)-2-amino-2-[(1S,2S)-2-carboxycycloprop1-yl]-3-(xanth-9-yl) propanoic acid] and noncompetitive mGluR5 antagonist 2-methyl-6-(phenylethynyl)-pyridine (MPEP), as well as lithium at concentrations found previously to be optimal for treating $d$ fmr 1 mutants (McBride et al., 2005). LY341495 is a very specific group II antagonist that has been shown to antagonize DmGluRA in the nanomolar range (Bogdanik et al., 2004). Although MPEP was developed as a noncompetitive antagonist of the vertebrate group I mGluR5, we have included it in our studies because the MPEP binding pocket of mGluR5 is more highly conserved with DmGluRA than any other vertebrate mGluRs and in previous experiments has similar activity to the known DmGluRA antagonists LY341495, MPPG $[(R S)$ - $\alpha$-methylserine$O$-phosphate], and MTPG [(RS)- $\alpha$-methyl-4-tetrazolylphenylglycine] and shows similar effects to that obtained by genetically reducing DmGluRA activity (Parmentier et al., 1996; Pagano et al., 2000; Malherbe et al., 2003; Bogdanik et al., 2004; McBride et al., 2005; Bolduc et al., 2008; Pan et al., 2008). However, because it has not been formally shown to be an antagonist of DmGluRA, it is therefore a putative DmGluRA antagonist.

Two different $p s n$-het genotypes ( $p s n \mathrm{~B} 3$ and $p s n$ I2) were treated with different drugs or non-drug-containing control vehicle solutions from days 6 to 29 of adulthood (after eclosion). Flies were then transferred to control food containing no drug for $1 \mathrm{~d}$ before being tested. Flies were treated with $5 \mathrm{~mm} \mathrm{NaCl}$ (ionic control for LiCl), $0.004 \%$ DMSO (the vehicle for LY341495), 5 mM LiCl (lithium), 8.6 $\mu \mathrm{M}$ MPEP, or 400 nM LY341495. Remarkably, treatment with LiCl, LY341495, or MPEP improved LDT performance in $p s n$-het flies (Fig. $3 H-J$ ). In contrast, no improvement was observed in flies treated with $\mathrm{NaCl}$ or DMSO (Fig. $3 K, L$ ). These experiments demonstrate that the impairment in LDT exhibited by the untreated $p s n$-het flies can be prevented by treatment with lithium, LY341495, and MPEP.

This result with LDT raised the possibility that treatment with lithium, LY341495, and MPEP might also prevent the agedependent impairment in short-term memory that is exhibited by the $p s n$-het males. Using the same set of pharmacologic treatments, we found that psn-het flies treated from 6 to $29 \mathrm{~d}$ after eclosion with $5 \mathrm{~mm}$ lithium, 8.6 $\mu \mathrm{M}$ MPEP, or $400 \mathrm{nM}$ LY341495 demonstrated intact short-term memory (Fig. 3M-O), whereas those treated with $5 \mathrm{~mm} \mathrm{NaCl}$ or $0.004 \%$ DMSO did not (Fig. $3 P, Q)$. This result demonstrates that the impairment in short- 


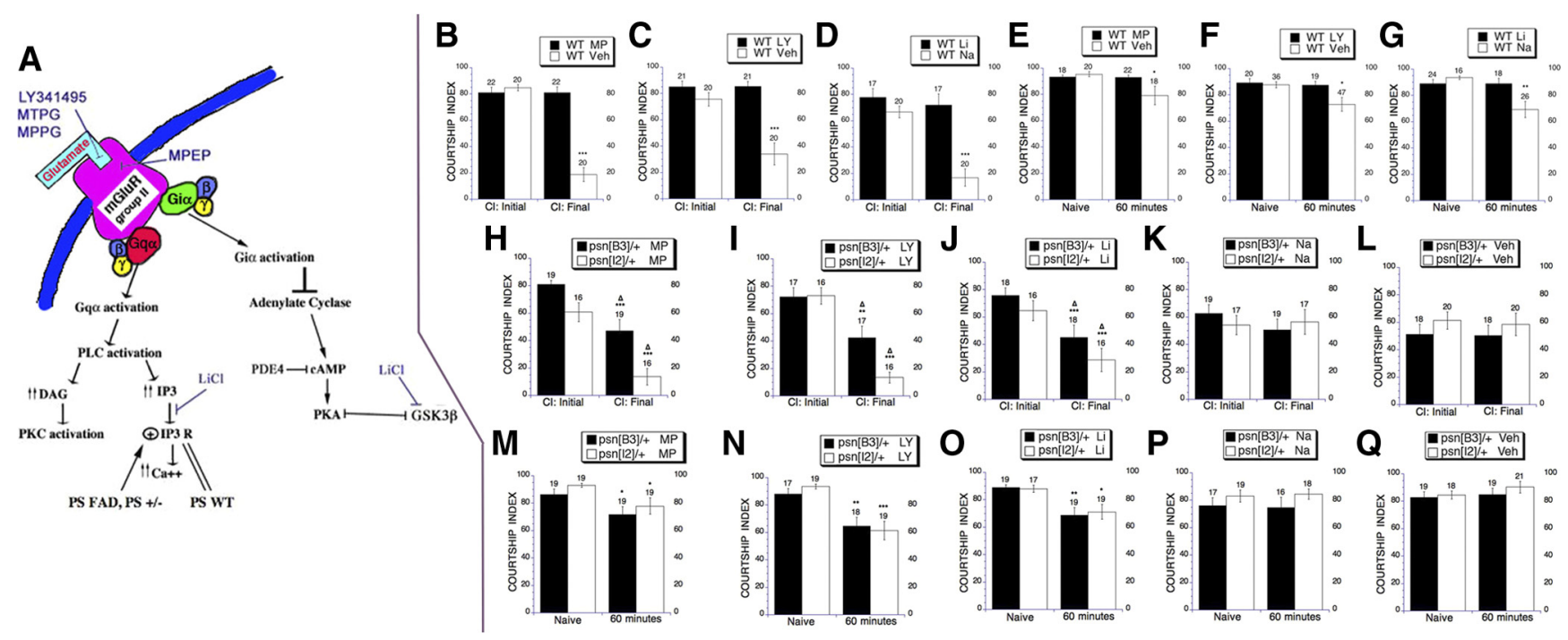

Figure 3. Pharmacologic treatments prevent impairments in learning during training and short-term memory in psn-het flies at $30 \mathrm{~d}$ of age. $A$, A diagram of the putative signaling in our AD model as well as that from the literature is shown. Arrows indicate activation or increases, and blunt ends indicate inhibition or decreases in activity or protein levels. The double line between wild-type presenilin and $I n s P_{3} R$ indicates an interaction that is neutral or inhibitory. Previous studies have established that group I $\mathrm{mGluRs}$ in mammals activate the $\mathrm{G}_{q}$ pathway, whereas the group II and group III $m$ GluRs activate the $G_{i}$ signaling pathway. However, there is accumulating evidence that, in mammals, group II mGluRs may activate the $G_{q}$ signaling pathway and induce long-term depression in a manner dependent on phospholipase C (PLC) and InsP ${ }_{3}$ R activity (Huang et al., 1997, 1999a,b; Otani et al., 1999, 2002), and group I mGluRs are capable of activating $\mathrm{G}_{\mathrm{i}}$ (Kreibich et al., 2004). We are outlining in this model the actions of DmGluRA in Drosophila, which is known to activate $G_{i}$ activity, and recent studies indicate that it may also activate $G_{q}$ activity, just as is the case of group II mGluRs in mammals (Pan et al., 2008). During activation, $\mathrm{G}_{q}$ activates $\mathrm{PLC}$, which produces $D A G$ and Ins $\mathrm{P}_{3}$. DAG and Ins $\mathrm{P}_{3}$ can activate $P K C$ and the Ins $P_{3} R$ to release calcium from the endoplasmic reticulum. $G \alpha_{\mathrm{i}}$ activation inhibits adenylate cyclase, thereby preventing an increase in CAMP in response to synaptic stimulation, which prevents the activation of CREB by PKA. Phosphodiesterase 4 (PDE4) breaks down cAMP levels. MPEP is a group I mGluR5 noncompetitive antagonist, which we use at high concentrations to block DmGluRA. LY341495 is a very specific competitive antagonist of DmGluRA (Bogdanik et al., 2004). LiCl has two main actions at therapeutic levels in cells, one of which is the lowering of Ins $P_{3}$ levels by inhibiting inositol monophosphatase and inositol polyphosphatase, thereby decreasing the synthesis of InsP $_{3}$, as well decreasing the rate at which it is recycled (Berridge, 1993; Takei et al., 1998; Williams et al., 2002). The second action of lithium is the inhibition of GSK-3 $\beta$ activity (Klein and Melton, 1996). It is through the aforementioned activities that we propose that these drugs may alter signaling in the Drosophila brain. $\boldsymbol{B}-\mathbf{G}$, Treatment of WT control flies (OreR) with the DmGluRA antagonist LY341495, the putative DmGluRA antagonist MPEP, or lithium during aging results in impairment of learning during training and short-term memory. WT control flies were raised on control food and then, after day 6 after eclosion, were placed on food containing either $8.6 \mu \mathrm{m}$ MPEP (MP) or vehicle (Veh) (B, $\boldsymbol{E}), 400 \mathrm{~nm}$ LY341495 (LY) or vehicle $($ Veh $)(\boldsymbol{C}, \boldsymbol{F})$, or $5.0 \mathrm{~mm}$ lithium (Li) or $5.0 \mathrm{~mm} \mathrm{NaCl}(\mathrm{Na})(\boldsymbol{D}, \boldsymbol{G})$ until day 29 and then were tested on day 30 . $\boldsymbol{H}-\mathbf{Q}$, Treatment of $p$ sn-hets with the DmGluRA antagonist LY341495, the putative DmGluRA antagonist MPEP, or lithium prevents the age-dependent impairments in learning during training and short-term memory observed in psn-het flies. psn-hets for the psn B3 and psn I2 alleles were raised on control food and then, at day 6 after eclosion, were placed on food containing $8.6 \mu \mathrm{MMPEP}(\boldsymbol{H}, \boldsymbol{M}), 400 \mathrm{~nm} \operatorname{LY} 341495(\boldsymbol{I}, \boldsymbol{N}), 5.0 \mathrm{~mm}$ lithium $(\boldsymbol{J}, \mathbf{0}), 5.0 \mathrm{~mm} \mathrm{NaCl}(\boldsymbol{K}, \boldsymbol{P})$, or $0.004 \%$ DMSO (L, Q) until day 29. Mean \pm SEM Cls are plotted. $n$ values are indicated above each bar for all groups. The levels of significance are indicated $\left({ }^{*} p<0.05,{ }^{* *} p<0.01\right.$, $\left.{ }^{* * *} p<0.001\right)$. A triangle indicates a $40 \%$ or greater reduction in courtship activity during the training session with a previously mated female $(\boldsymbol{H}-\boldsymbol{L})$. OreR flies that were treated with MPEP, LY341495, and lithium lacked detectable learning during training $(\boldsymbol{B}-\boldsymbol{D})$ or short-term memory $(\boldsymbol{E}-\boldsymbol{G})$. OreR flies treated with DMSO or NaCl displayed normal learning during training $(\boldsymbol{B}-\boldsymbol{D})$ and short term memory $(\boldsymbol{E}-\boldsymbol{G})$. psn-het flies that were treated with LY341495, MPEP, or lithium demonstrated intact learning during training $(\boldsymbol{H}-\boldsymbol{J})$ and intact short-term memory $(\boldsymbol{M}-\mathbf{0})$ at $30 \mathrm{~d}$ of age. In contrast, psn-het flies that were on food containing $\mathrm{NaCl}$ or DMSO did not display learning during training $(\boldsymbol{K}, \boldsymbol{L})$ or short-term memory $(\boldsymbol{P}, \boldsymbol{Q})$ at $30 \mathrm{~d}$ of age.

term memory exhibited by 30 -d-old psn-het flies can be prevented by treatments aimed at reducing DmGluRA activity. In contrast, prolonged treatment of OreR (WT) flies with lithium, LY341495, and MPEP impaired LDT and short-term memory, whereas vehicle treatment did not (Fig. $3 B-G$ ).

The rescue that we observe when $p s n$-hets are treated with LY341495, MPEP, or lithium is analogous to the results, we obtained when we treated $d f m r 1$ mutants with these same drugs (McBride et al., 2005). The similarity of these results suggests that both $p s n$-hets and $d f m r 1$ mutants display cognitive deficits that are attributable to enhanced DmGluRA signaling. However, another possibility is that these drug treatments represent some type of panacea that can rescue any cognitive deficit observed in flies. With this second possibility in mind, we tested the effect of treating another disease model that displays age-onset loss of shortterm memory with LY341495, MPEP, and lithium.

We have found that expression of human wild-type $\alpha$-synuclein in the mushroom bodies of the fly leads to age-dependent loss of short-term memory. The mushroom bodies are required for short-term memory formation in the conditioned courtship paradigm (Joiner and Griffith, 1999; McBride et al., 1999). In controls for these flies, short-term memory is intact at $30 \mathrm{~d}$ of age (supplemental Fig. S8 A, available at www.jneurosci.org as supplemental material). In flies expressing human wild-type $\alpha$-synuclein in the mushroom bodies, short-term memory is intact at $5 \mathrm{~d}$ of age but is impaired at $30 \mathrm{~d}$ of age (supplemental Fig. S8 $B$, available at www.jneurosci.org as supplemental material). Treatment of these flies with lithium, LY341495, or MPEP failed to rescue this deficit (supplemental Fig. $S 8 C, D$, available at www.jneurosci.org as supplemental material), indicating that rescue of cognitive deficits in the $p s n$-hets by the drug treatments is disease specific and may not necessarily be extrapolated to other disease models displaying age-dependent cognitive impairments.

\section{Morphological analysis of heterozygous psn brain tissues}

The age-dependent impairments in LDT and short-term memory observed in the psn-het flies could possibly be attributable to the loss of critical neurons as a result of cell death. There is a body of literature describing loss of synapses and neurons in the brains of Alzheimer's patients and in related mouse models (Selkoe, 2002; Mattson, 2004; Walsh and Selkoe, 2004; Hardy, 2006; Small and Gandy, 2006). To determine whether neuronal loss could account for the cognitive loss, we performed TUNEL staining on 

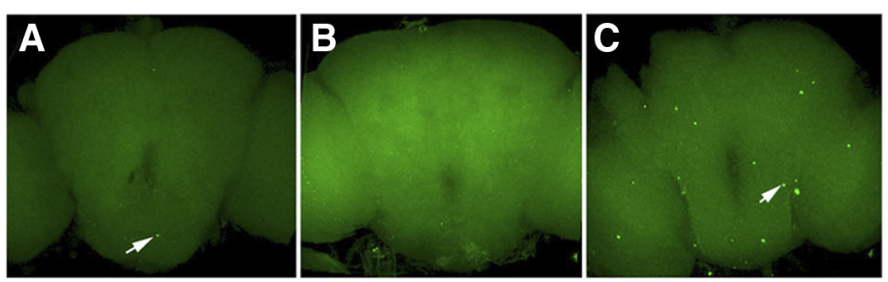

D Number of Cell Death Foci
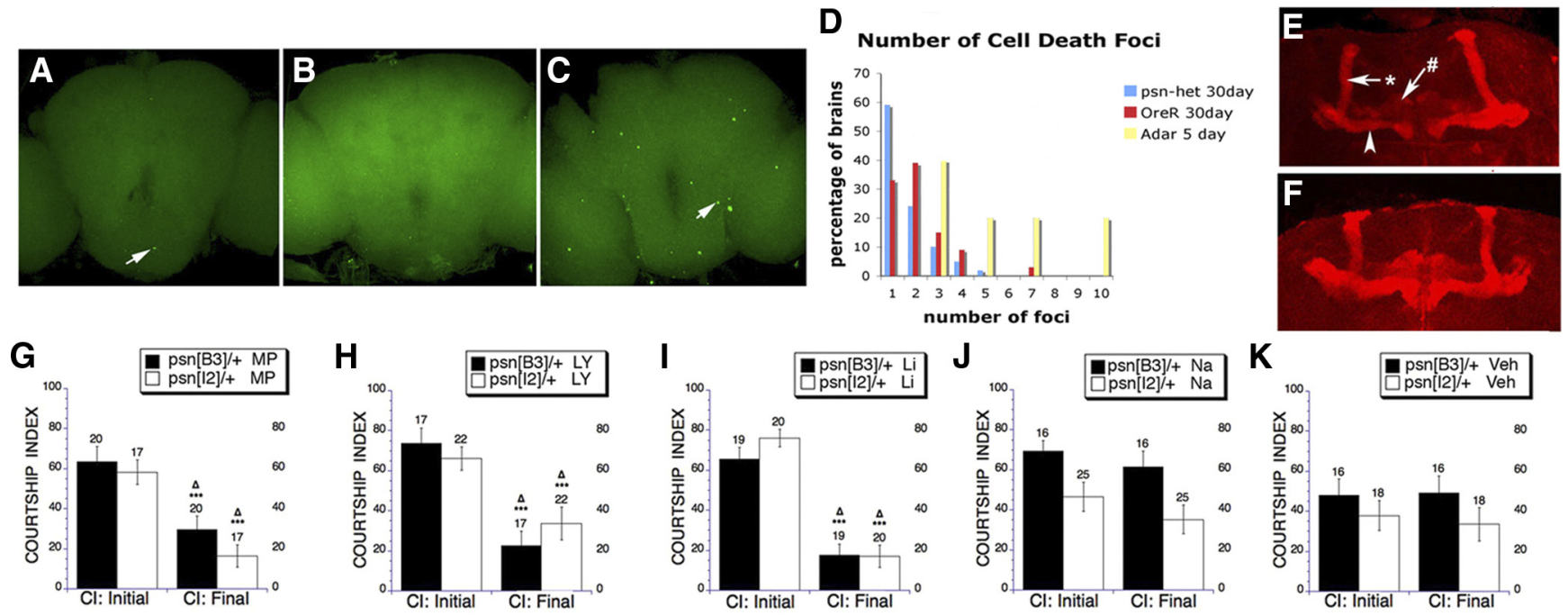

mber of foci
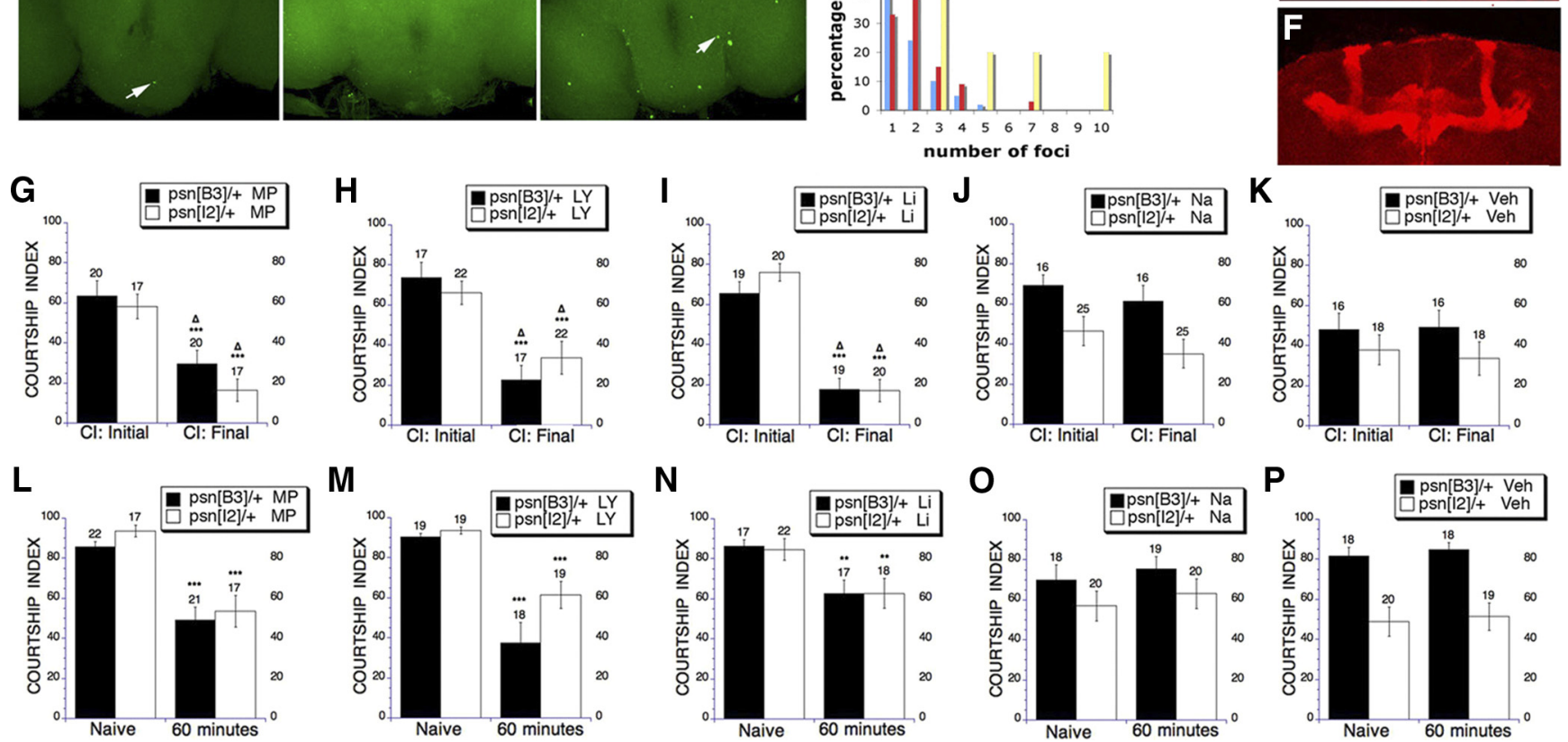

M

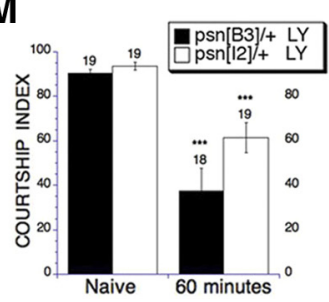

$\mathbf{N}$

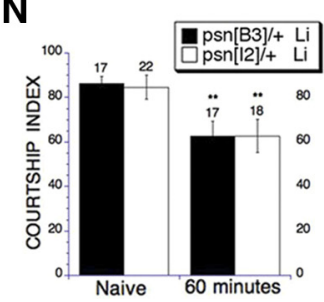

$\mathrm{J}$

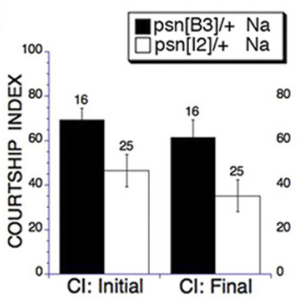

0

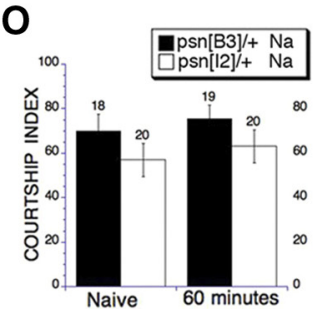

$K$

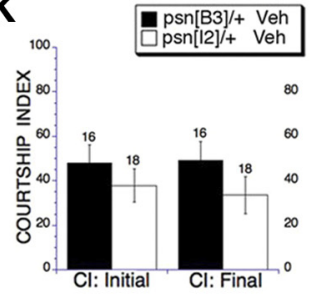

$P$

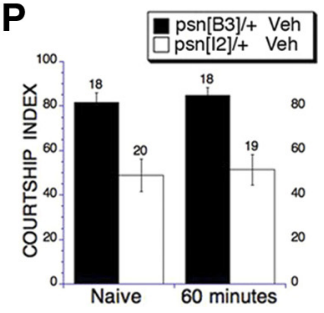

Figure 4. Cell death and morphology in 50-d-old psn-het flies. Pharmacologic treatments can reverse impairments in learning during training and short-term memory in $p s n$-het flies. $\boldsymbol{A}$ - $\boldsymbol{C}$, Analysis of cell death in aged psn-het, OreR, and Adar mutant brains. TUNEL staining was performed on 50-d-old (negative control) OreR (A), 50-d-old psn-het ( $\boldsymbol{B}$ ), and 5-d-old (positive control) Adar mutant brains $(\boldsymbol{C})$. The brains were examined by confocal microscopy to identify cells undergoing cell death. Foci containing at least one cell undergoing cell death are denoted by white arrows. Maximum projections, as shown in $\boldsymbol{A}-\boldsymbol{C}$, made from confocal stacks of entire brains were examined for cell death foci. The number of foci in the central brain region for each brain was scored. The distribution of the number of cell death foci versus the percentage of brains with such number of foci is shown in $\boldsymbol{D}$. The majority of $p s n$-het brains lacked any detectable cell death ( $n=41$ ). Those that did had less than five foci, and there was no consistent location in the brain in which the foci were detected. Similar results were obtained with the 0 reR brains ( $n=33$ ). Cell death foci were detected in all Adar mutant brains $(n=5)$, which have been described previously to undergo massive cell loss via cell death (Palladino et al., 2000). Fifty-day-old 0 reR $(\boldsymbol{E})$ and psn-het $(\boldsymbol{F})$ brains were stained with anti-Fasll and examined by confocal microscopy to examine the integrity of the mushroom bodies. This antibody strongly labels the $\alpha$-lobes (white arrow with ${ }^{*}$, shown in $\boldsymbol{E}$ ) and $\beta$-lobes (arrowhead shown in $\boldsymbol{E}$ ) and weakly stains the $\gamma$-lobes (white arrow with \#, shown in $\boldsymbol{E}$ ). There was no detectable difference in the morphology of the mushroom bodies between OreR ( $n=$ 21) and psn-het ( $n=18)$ brains. G-P, Treatment with LY341495, MPEP, or lithium reverses the age-dependent impairments in learning during training and short-term memory observed in psn-het flies. psn-hets for the psn B3 and psn I2 alleles were raised on control food and then, at day 30 after eclosion, were placed on food containing $8.6 \mu M M P E P(G, L), 400 \mathrm{~nm} L \mathbf{L} 341495$ ( $\boldsymbol{H}, \boldsymbol{M}), 5.0 \mathrm{~mm}$ lithium $(\boldsymbol{I}, \boldsymbol{N}), 5.0 \mathrm{~mm} \mathrm{NaCl}(\boldsymbol{J}, \mathbf{0})$, or 0.004\% DMSO $(\boldsymbol{K}, \boldsymbol{P})$ until day 44 and were tested on day 45 . Mean \pm SEM Cls are plotted, and $n$ values are indicated above each bar for all groups. The levels of significance are indicated $\left({ }^{* *} p<0.01,{ }^{* * *} p<0.001\right)$. A triangle indicates a $40 \%$ or greater reduction in courtship activity during the training session with a previously mated female $(\mathbf{G}-\boldsymbol{P})$. psn-het flies that were treated with LY341495, MPEP, or lithium demonstrated intact learning during training ( $\mathbf{G}-\boldsymbol{I})$ and intact short-term memory $(\boldsymbol{L}-\boldsymbol{N})$ at $45 \mathrm{~d}$ of age. In contrast, $p$ sn-het flies that were on food containing $\mathrm{NaCl}$ or DMSO did not display learning during training $(\boldsymbol{J}, \boldsymbol{K})$ or short-term memory $(\mathbf{O}, \boldsymbol{P})$ at $45 \mathrm{~d}$ of age.

aged $p s n$-het and control flies. Additionally, we examined the morphology of the MBs in aged psn-het brains, which are required for short-term memory in the conditioned courtship paradigm (Joiner and Griffith, 1999; McBride et al., 1999). In the brains of 50-d-old psn-het and OreR flies, we failed to detect any consistent neuronal loss by TUNEL staining or any gross defects in $\mathrm{MB}$ morphology, indicating that the observed cognitive loss is most likely not attributable to an age-dependent loss of neurons or breakdown in $\mathrm{MB}$ integrity (Fig. $4 A-F$ ). Consistent cell death was observed in 5-d-old (positive control) Adar mutant brains, which have been shown previously to undergo neuronal cell loss (Fig. 4C,D) (Palladino et al., 2000).

\section{Reversal of the learning during training and short-term memory impairments}

Because the brain tissue of the aged psn-het flies appears to be morphologically normal, we considered the possibility that the age-related behavioral phenotypes could be reversed after they have already become established. Because the age-dependent impairments in LDT and short-term memory could be prevented by treatment with LY341495, MPEP, or lithium, we next examined whether these phenotypes could be reversed by these treatments. Reversal of the deficits would further indicate that the agedependent cognitive impairments were likely the result of physiological neuronal defects (disrupted intracellular signaling possibly followed by synapse loss) and not cell death. Using the same two genotypes ( $p s n$-hets with decreased presenilin activity) that were subjected to treatments as young adults (Fig. 3), we now began treatments at day 30 and treated until day 44 , testing at $45 \mathrm{~d}$ of age. As above, flies were treated with $5 \mathrm{~mm} \mathrm{NaCl}, 0.004 \%$ DMSO, 5 mm lithium, 8.6 $\mu$ M MPEP, or 400 nM LY341495. Treatment with LY341495 and the putative DmGluRA antagonist MPEP, as well as lithium, reversed the LDT (Fig. 4G-I) and short-term memory (Fig. $4 L-N$ ) phenotypes in both lines tested. In contrast, treatment with $5 \mathrm{~mm} \mathrm{NaCl}$ and the DMSO vehicle from days 30 to 44 failed to restore normal LDT (Fig. $4 J, K$ ) or short-term memory (Fig. 4O,P) in either of the two lines. This demonstrates that the impairments in LDT and short-term memory exhibited by untreated $p s n$-het flies can be reversed by treatments aimed at reducing DmGluRA activity. This finding is significant considering that our results may be relevant to the pathogenesis of Alzheimer's disease in humans, which is only 
A
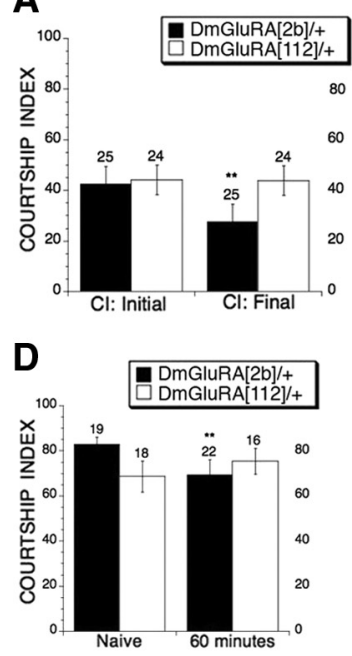

B

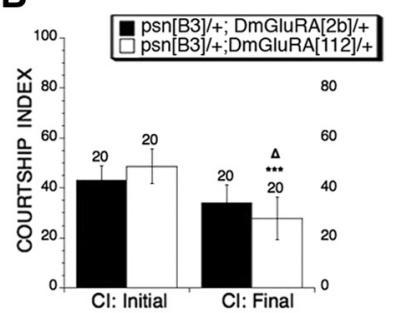

E

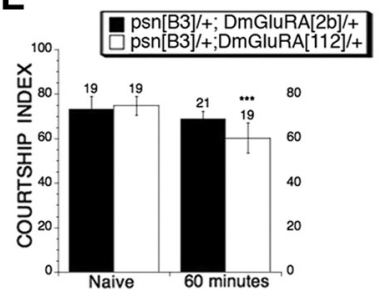

C

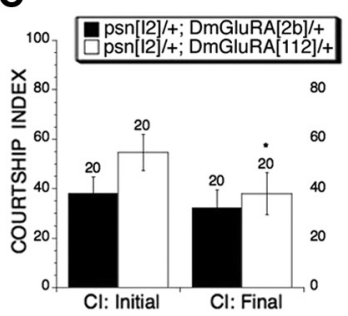

$F$

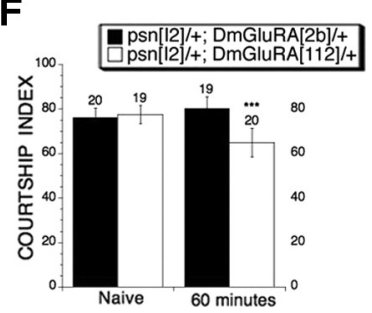

Figure 5. A genetic reduction of DmGluRA rescues short-term memory in psn-het flies at $30 \mathrm{~d}$ of age. All flies were tested at $30 \mathrm{~d}$ of age for learning during training or short-term memory. Mean \pm SEM Cls are plotted, and $n$ values are indicated above each bar for all groups. The levels of significance are indicated $\left({ }^{*} p<0.05,{ }^{* *} p<0.01,{ }^{* *} p<0.001\right)$. A triangle indicates a $40 \%$ or greater reduction in courtship activity during the training session with a previously mated female $(\boldsymbol{A}-\boldsymbol{C}) . D m G / u R A^{112}$ is a null allele and $D m G l u R A^{2 b}$ is a precise excision wild-type control allele of DmGluRA. $\boldsymbol{A}$, Heterozygosity for the DmGluRA null impairs learning during training. Heterozygosity of DmGluRA rescues learning during training in psn-het B3 (B) and psn-het I2 (C) flies. D, Heterozygosity for the DmGluRA null impairs short-term memory. $\boldsymbol{E}, \boldsymbol{F}$, Heterozygosity of DmGluRA rescues short-term memory in psn-het B3 $(\boldsymbol{E})$ and psn-het $\mathrm{I} 2(\boldsymbol{F})$ flies.

recognized after the onset of cognitive impairments, emphasizing the need to develop therapeutic strategies that can be implemented after the appearance of overt disease symptoms.

\section{Genetic reduction of DmGluRA prevents the onset of LDT and short-term memory defects in aged $p s n$-hets}

To validate the pharmacological studies described above, we tested the effect of genetically reducing the level of DmGluRA, the only metabotropic glutamate receptor in the Drosophila genome (Bogdanik et al., 2004), in the psn-het background. Given the reported binding specificities of MPEP, the ability of MPEP treatment to phenocopy genetic loss of function in DmGluRA mutants, the reported actions of lithium, and the fact that LY341495 has been shown to be a very efficient antagonist of DmGluRA, our drug treatments should reduce DmGluRA signaling activity (Bogdanik et al., 2004; McBride et al., 2005). If our observed rescue is occurring through reduction of DmGluRA signaling activity, our expectation is that genetic reduction of DmGluRA should similarly provide some level of rescue of the age-onset cognitive deficits. To perform this test, we used the previously described null allele of DmGluRA (DmGluRA $\left.{ }^{112}\right)$ and precise excision wild-type allele $\left(D m G l u R A^{2 b}\right)$ (Bogdanik et al., 2004).

In testing DmGluRA heterozygous flies alone, we found that, at $30 \mathrm{~d}$ of age, they display a defect in LDT as well as in short-term memory (Fig. $5 A, D$ ), which is similar to what we observed when OreR control flies were treated with LY341495, MPEP, and LiCl (Fig. $3 B-G$ ). In contrast, the wild-type controls for these lines displayed intact LDT and short-term memory at $30 \mathrm{~d}$ of age (Fig. $5 A, D)$. Consistent with our hypothesis, we find that reducing the gene dosage of the DmGluRA receptor by $50 \%$ in the psn-het background prevents the age-onset loss of LDT and short-term memory observed previously at $30 \mathrm{~d}$ of age, whereas introduction of the precise excision allele has no effect (Fig. $5 B, C, E, F$ ). These results validate the pharmacological studies described above and again indicate that enhanced DmGluRA signaling contributes to the age-onset cognitive deficits. The results obtained from the DmGluRA heterozygous flies and OreR WT flies treated with MPEP, LY341495, and lithium, as described above, all indicate that LDT and short-term memory are sensitive to a reduction in the activity of this receptor as well.

\section{Genetic reduction of the inositol polyphosphate 1-phosphatase prevents age-onset cognitive defects in the psn-hets}

The results of our pharmacological and genetic analysis indicate that reducing DmGluRA signaling rescues age-onset cognitive deficits in $p s n$-hets. Activation of DmGluRA through the $\mathrm{G}_{\mathrm{i}}$-coupled pathway lowers cAMP signaling and through potential $\mathrm{G}_{\mathrm{q}}$ coupling should increase Ins $\mathrm{P}_{3} \mathrm{R}$-mediated calcium signaling (Fig. 3A) (McBride et al., 2005). Lithium as well as DmGluRA antagonists should act to increase CAMP-mediated signaling by increasing PKA activity and may also act to lower InsP $\mathrm{P}_{3} \mathrm{R}$-mediated calcium signaling (Fig. $3 A$ ).

Previous studies indicate that presenilin proteins bind to the inositol triphosphate receptor, and expression of mutant forms of presenilin protein lead to elevated $\mathrm{Ca}^{2+}$ signaling (Stutzmann et al., 2004; Cheung et al., 2008). The mechanism linking mGluR activity to increased $\mathrm{InsP}_{3} \mathrm{R}$ activity is shown in Figure $3 \mathrm{~A}$. Decreased presenilin function by FAD mutations has been shown to increase the sensitivity of the $\operatorname{Ins}_{3} \mathrm{R}$ to Ins $\mathrm{P}_{3}$. This means that, in response to glutamate release after synaptic stimulation, the mGluR will be activated, thereby activating $G_{q}$ and $G_{i}$. The $G_{q}$ activation will in turn generate $\operatorname{InsP}_{3}$. Because there is less wildtype presenilin present to basally inhibit the sensitivity of the Ins $\mathrm{P}_{3} \mathrm{R}$ to InsP $\mathrm{P}_{3}$, there will be enhanced Ins $\mathrm{P}_{3} \mathrm{R}$-mediated calcium release in response to physiologic synaptic stimulation. To test whether the rescue we observe with genetic and pharmacological manipulation aimed at reducing DmGluRA activity is possibly working by lowering enhanced $\operatorname{Ins}_{3} \mathrm{R}$ activity, we have undertaken manipulations to directly lower $\operatorname{Ins}_{3} \mathrm{R}$ activity. Toward this goal, we tested the effect of genetically reducing the levels of the IPPase locus. IPPase as well as IMPase are directly inhibited by lithium and are required for $\mathrm{InsP}_{3}$ recycling and synthesis (Berridge, 1993). Genetic reduction of IPPase has been shown to reduce InsP $\mathrm{P}_{3} \mathrm{R}$ signaling in flies (Acharya et al., 1998). We tested two loss-of-function alleles (IPPase1 and IPPase3) (Acharya et al., 1998) as heterozygotes and found that, at $30 \mathrm{~d}$ of age, heterozygous males for one allele (IPPase1) lacked significant LDT, but heterozygote males for both alleles displayed normal short-term memory (Fig. 6A,D). When crossed in the psn-het backgrounds, the IPPase $e^{3}$ allele prevented loss of LDT in both $p s n$ alleles and the $I_{P P a s e}{ }^{1}$ allele prevented this loss of LDT in the $p s n^{B 3}$-het background (Fig. $6 \mathrm{~B}, \mathrm{C}$ ). Both alleles of IPPase prevented loss of shortterm memory in both $p s n$-het lines (Fig. $6 E, F)$. These results indicate that reduction of IPPase activity can prevent the ageonset cognitive deficits observed with the $p s n$-het flies. Next we directly tested whether genetic reduction of the $\operatorname{Ins} P_{3} R$ gene itself could modulate the age-dependent $p s n$-het phenotypes. To test the effect of genetically reducing $\mathrm{Ins}_{3} \mathrm{R}$ activity, we used three 
different strength alleles: a hypomorph (wc361), a molecular null (90B0), and an antimorphic allele (wc703) (Venkatesh and Hasan, 1997; Deshpande et al., 2000). At $30 \mathrm{~d}$ of age, heterozygous males for these alleles display weak ( $w c 703)$ or no detectable (wc361 and 90B0) LDT, and all display normal short-term memory (Fig. $7 A, E)$. When introduced into the $p s n$-het background, two of these alleles prevented loss of LDT in the $B 3$ allele of $p s n$ (Fig. $7 B-D$ ), and all three alleles prevent the loss of short-term memory in both $p s n$ alleles at $30 \mathrm{~d}$ of age (Fig. $7 F-H$ ). The $90 B 0$ allele continues to prevent this loss of short-term memory at $40 \mathrm{~d}$ of age (Fig. $7 I)$. These results suggest that a reduction in $\operatorname{Ins} P_{3} R$-mediated $\mathrm{Ca}^{2+}$ release is also another potential route to ameliorate the age-onset cognitive deficits associated with reduced $p s n$ levels.

\section{Discussion}

To date, all cases of early onset familial forms of Alzheimer's disease are attributable to mutations in a single copy of PS1, PS2, or APP. The large number of different mutations in the PS1 and PS2 genes that cause $\mathrm{AD}$ as well as analysis of the protease function of FAD mutants is consistent with a loss of function of PS1 and PS2 as a contributing cause of FAD (De Strooper, 2007; Hardy, 2007; Shen and Kelleher, 2007). This interpretation of the data suggests that the levels or activity of PS1, PS2, and APP are crucial for maintaining normal cognition throughout life. Based on these studies, we have explored whether this dosage sensitivity of presenilin also exists in Drosophila by examining the cognitive capabilities of $p s n$-het flies in young and progressively aged $p s n$-het flies. Using a conditioned courtship paradigm, we have found that deficits in LDT and short-term memory develop in the $p s n$-het flies with age. These results further strengthen the hypothesis that some aspects of FAD and possibly AD may be caused by reduced levels of $p s n$ activity.

\section{The appearance of cognitive deficits before any detectable neuronal loss}

Previous Drosophila AD models have revealed phenotypes that have parallels with those observed in mouse models and human patients. These fly models have been based on ectopic expression of either human tau or human $\mathrm{A} \beta_{40}$ or $\mathrm{A} \beta_{42}$ peptides and have been shown to exhibit either hyperphosphorylated tau or aggregations of $A \beta$ that result in neurodegeneration (Wittmann et al., 2001; Iijima et al., 2004; Mershin et al., 2004; Crowther et al., 2005). Additionally, it has been demonstrated that expression of human tau, $\mathrm{A} \beta_{40}$, or $\mathrm{A} \beta_{42}$ leads to memory deficits (Iijima et al., 2004; Mershin et al., 2004). In these models, memory deficits are already present in young adult flies. In contrast, we have uncovered cognitive impairments that are age dependent in the $p s n$-het flies and occur before any detectable loss of neurons. In studying the psn-het flies, we detect a clear deficit in LDT and short-term memory that appeared by $30 \mathrm{~d}$ of age. Our examination for cell death was done on $p s n$-hets that were at least $50 \mathrm{~d}$ old, e.g., $20 \mathrm{~d}$ older than when the defects in LDT and short-term memory are
B C
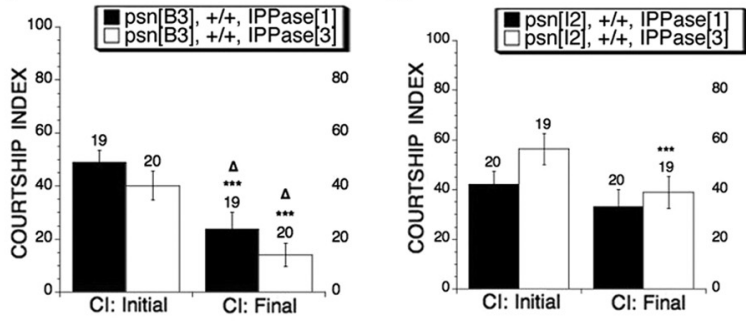

$E$

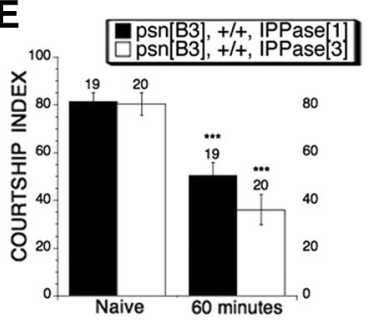

$\mathbf{F}$

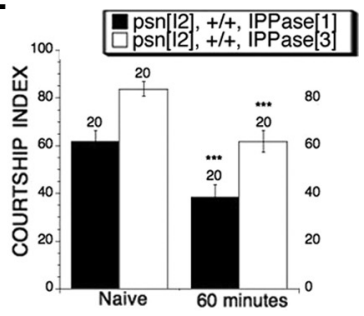

Figure 6. A reduction in IPPase expression rescues short-term memory in psn-het flies at $30 \mathrm{~d}$ of age. All flies were tested does not. $\boldsymbol{D}$, Heterozygosity for the IPPase loss-of-function mutants does not impair short-term memory. $\boldsymbol{E}, \boldsymbol{F}$, Heterozy(tion mutants rescues short-term memory in psn-het B3 $(\boldsymbol{E})$ and psn-het $\mathrm{I} 2(\boldsymbol{F})$ flies.

detected. Consistent with this finding, we were able to reverse the cognitive deficits by initiating treatment at day 30 , which would likely not occur if neuronal loss were the cause of the cognitive decline.

Although neuronal death is typical of $\mathrm{AD}$, cognitive impairment precedes neuronal death in humans and animal models. Indeed, recent studies have indicated that synapse loss is better correlated with memory impairment than the histopathological hallmarks of plaques and tangles in $\mathrm{AD}$ patients (DeKosky and Scheff, 1990; Terry et al., 1991; Coleman and Yao, 2003). In fact, memory impairment in Alzheimer's disease can occur in the absence of plaques and tangles in animal models (Oddo et al., 2003; Gong et al., 2004; Iijima et al., 2004; Mershin et al., 2004; Billings et al., 2005) or in FAD patients (Raux et al., 2000; Amtul et al., 2002; Dermaut et al., 2004; Halliday et al., 2005). Additionally, within 2-4 years of $\mathrm{AD}$ onset, 25-35\% loss of synapses is observed in biopsies of frontal cortex in afflicted patients (Davies et al., 1987). Furthermore, synaptic function may be impaired even before synaptic loss occurs in animal models of $\mathrm{AD}$ as well as in patients (Oddo et al., 2003; Palop et al., 2003; Westphalen et al., 2003; Yao et al., 2003). Thus, our results add to a growing body of literature that indicates that loss of synaptic plasticity can occur before or without plaque or tangle formation or neuronal loss. Our results also demonstrate that this loss of synaptic plasticity can occur solely as a result of a reduction in psn activity, in the absence of $\mathrm{A} \beta$ accumulation, which does not occur in Drosophila.

\section{Pharmacological rescue of LDT and short-term memory}

In a genetic search for pathways affected by a reduction in $p s n$ levels, we identified a strong genetic interaction between $p s n$ and $d f m r 1$. Because this genetic interaction revealed a phenotype in courtship that was rescued previously in $d f m r 1$ mutant flies by treatment with DmGluRA antagonists and lithium, we explored the possibility that these drugs might have efficacy in treating the 
A

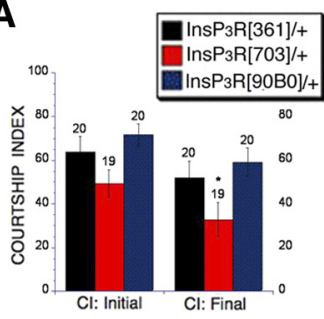

B

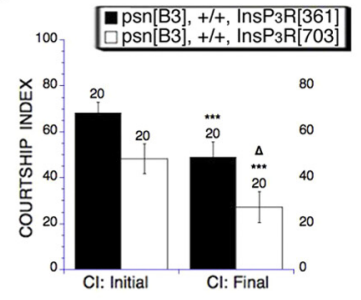

C

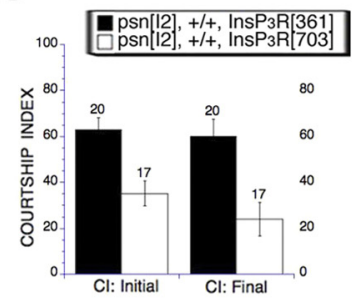

D

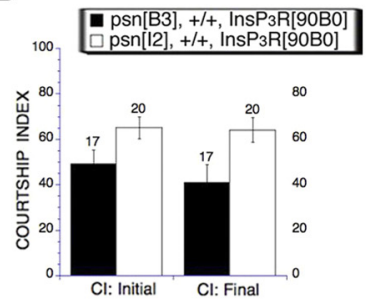

E

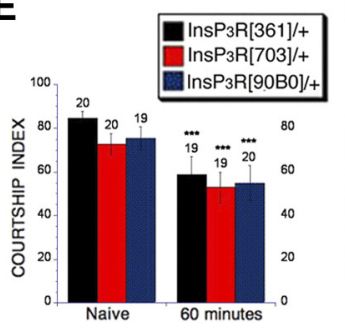

$F$

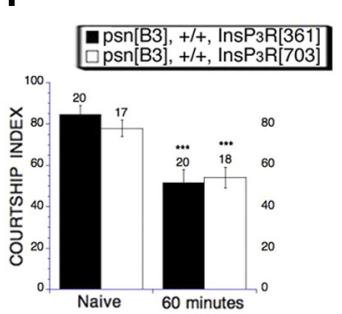

G

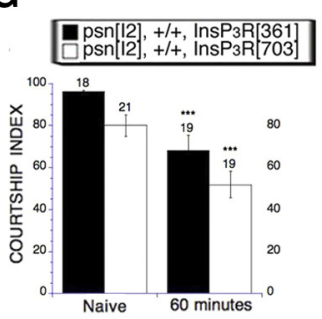

H

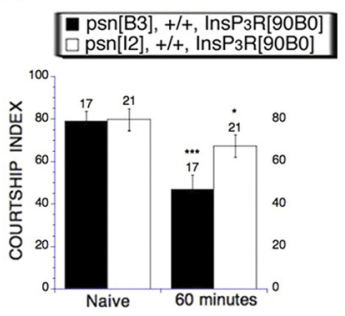

1

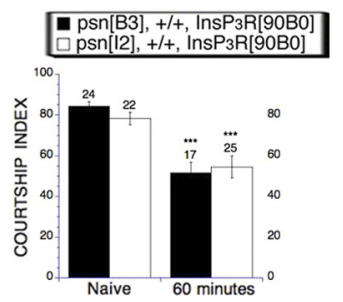

Figure 7. A reduction in $/ n s P_{3} R$ expression rescues short-term memory in $p s n$-het flies at 30 and 40 d of age. All flies were tested at either 30 or 40 d of age for learning during training or short-term memory. Mean \pm SEM Cls are plotted, and $n$ values are indicated above each bar for all groups. The levels of significance are indicated $\left({ }^{*} p<0.05\right.$, $\left.{ }^{* * *} p<0.001\right)$. A triangle indicates a $40 \%$ or greater reduction in courtship activity during the training session with a previously mated female $(\boldsymbol{A}-\boldsymbol{D})$. $\boldsymbol{A}$, Heterozygosity for the $I n s P_{3} R$ loss-of-function mutants 361 and $90 B 0$ impairs learning during training, whereas heterozygosity for the $I n s P_{3} R$ loss-of-function mutant 703 does not completely abrogate learning during training. $B$, Heterozygosity of the $/ n s P_{3} R$ loss-of-function mutants 703 and 361 rescues learning during training in psn-het $B 3$ flies. $C$, Heterozygosity of the $I n s P_{3} R$ loss-of-function mutants 703 and 361 fails to rescue learning during training in $p s n$-het 12 flies. $D$, Heterozygosity for the $I n s P_{3} R$ loss-of-function mutant $90 B 0$ does not rescue learning during training in psn-het $B 3$ or psn-het 12 flies. $E$, Heterozygosity for the $/ n s P_{3} R$ loss-of-function mutants does not impair short-term memory. $\boldsymbol{F}, \boldsymbol{G}$, Heterozygosity of the Ins $P_{3} R$ loss-of-function mutants 703 and 361 rescues short-term memory in psn-het B3 (F) and psn-het I2 (G) flies. $\boldsymbol{H}, \boldsymbol{I}$, Heterozygosity of the Ins $P_{3} R$ loss-of-function mutant $90 \mathrm{BO}$ rescues short-term memory in psn-het $\mathrm{B} 3$ and $p 5 n$-het $\mathrm{I2}$ flies at $30 \mathrm{~d}(\boldsymbol{H})$ and $40 \mathrm{~d}(\boldsymbol{I})$ of age.

age-onset phenotypes of the psn-hets. Consistent with our findings, recent studies of mouse Alzheimer's disease models and of afflicted humans have suggested that calcium signaling is enhanced and cAMP signaling may be decreased (Selkoe, 2002; Gong et al., 2004; Mattson, 2004; Walsh and Selkoe, 2004). We propose that these two signaling pathways are downstream of DmGluRA signaling (Fig. 3A).

In our studies, we demonstrated that treatment with lithium, the DmGluRA antagonist LY341495, and the putative DmGluRA antagonist MPEP prevented age-dependent impairments in psnhet flies at $30 \mathrm{~d}$ of age and can reverse LDT and short-term memory impairments if treatment is begun at $30 \mathrm{~d}$ of age, a time point after the deficits appear. These treatments should function to counteract decreased cAMP signaling and may counteract increased InsP ${ }_{3} \mathrm{R}$-mediated calcium release (Fig. $3 A$ ).

The successful treatments of the $p s n$-hets are consistent with results from two studies in mouse models of $\mathrm{AD}$, both of which demonstrated improved cognition through pharmacological treatment without effects on $\mathrm{A} \beta$ plaque burden. First, Gong et al. (2004) demonstrated that increasing cAMP levels can rescue behavioral plasticity, and second, Malm et al. (2007) showed that indirectly inhibiting GSK-3 $\beta$ activity rescues behavioral plasticity. The results from our studies demonstrate that treatment with lithium, LY341495, or MPEP can rescue cognitive loss attributable to reduced $p s n$ activity, a condition we propose exists in FAD and possibly sporadic AD. We therefore suggest that lithium and mGluR antagonists should be considered for additional study as potential agents for therapeutic treatment of cognitive deficits associated with Alzheimer's disease.

\section{Genetic reduction of the $\operatorname{InsP}_{3} \mathrm{R}$ pathway also prevents age-onset cognitive decline}

We wanted to further elucidate the pathways downstream of DmGluRA that might be responsible for the rescue observed when the DmGluRA activity is reduced, genetically or pharmacologically. Lithium treatment and decreases in mGluR activity both lower $\mathrm{Ins}_{3} \mathrm{R}$-mediated calcium signaling in vertebrates. In our genetic tests, we found that genetic reduction of $\operatorname{Ins}_{3} \mathrm{R}$ mediated calcium signaling provides similar rescue to that observed when DmGluRA activity is reduced genetically. By testing multiple alleles of IPPase as well as $\operatorname{Ins}_{3} \mathrm{R}$, we found that, in general, loss-of-function mutants of both genes provided rescue of age-onset deficits of LDT and short-term memory in the psn-hets.

The Ins $\mathrm{P}_{3} \mathrm{R}$ is an endoplasmic reticulum localized $\mathrm{Ca}^{2+}$ channel that releases $\mathrm{Ca}^{2+}$ from the endoplasmic reticulum into the cytoplasm in response to $\mathrm{Ins}_{3}$ binding. It was demonstrated recently that FAD mutations of presenilin expressed in cells resulted in increased sensitivity to $\mathrm{InsP}_{3}$-mediated $\mathrm{Ca}^{2+}$ release, leading to enhanced cytoplasmic concentrations of $\mathrm{Ca}^{2+}$ (Cheung et al., 2008). These results fit with previous studies in which both FAD mutations and loss of functional activity of wildtype presenilin have been linked to increases in $\operatorname{Ins}_{3} \mathrm{R}$-mediated calcium signaling in cell culture and transgenic mouse models of AD (Peterson et al., 1988; Huang et al., 1991; Ito et al., 1994; Tatebayashi et al., 1995; Hirashima et al., 1996; Etcheberrigaray et al., 1998; Stutzmann et al., 2004). Our results demonstrating that pharmacological treatment with drugs that should reduce DmGluRA activity, as well as genetic reduction of DmGluRA, IPPase, and the $\mathrm{InsP}_{3} \mathrm{R}$ are consistent with the hypothesis that reduction in this $\mathrm{Ca}^{2+}$ release mechanism might ameliorate the age-onset cognitive deficits associated with AD. Moreover, these results provide the first test of the pathogenic nature of enhanced Ins $\mathrm{P}_{3} \mathrm{R}$-mediated calcium signaling in $\mathrm{AD}$. Previous studies have speculated on the pathogenic nature of this calcium signaling but could not rule out the possibility that these changes were compensatory in $\mathrm{AD}$. Herein we were able to demonstrate a rescue of 
cognitive deficits by decreasing this signaling, indicating that upregulation of this pathway leads to cognitive loss over time.

In conclusion, our study of Drosophila psn haploinsufficiency contributes to the understanding of age-onset cognitive loss and provides a new model to study aspects of Alzheimer's disease. We examined several phases of learning and memory in young and older Drosophila adults and identified age-dependent cognitive impairments in learning during training and short-term memory. We have demonstrated that lithium treatment can rescue cognition in an animal model of AD. These results are in contrast to a previous attempt with lithium treatment in a mouse model of $\mathrm{AD}$ that failed to rescue working memory impairments (Caccamo et al., 2007). We have additionally identified and demonstrated the efficacy of mGluR antagonists as a novel therapeutic target for the treatment of the cognitive deficits associated with $\mathrm{AD}$. Our results also indicate that lowering IPPase activity or lowering InsP $\mathrm{P}_{3} \mathrm{R}$-mediated calcium signaling can rescue cognitive loss. Finally, this study demonstrates that reversal of memory impairment after onset can be obtained by treatment with either mGluR antagonists or lithium. These results suggest novel therapeutic targets that may have relevance for treatment of $\mathrm{AD}$ to be explored in other animal models.

\section{References}

Acharya JK, Labarca P, Delgado R, Jalink K, Zuker CS (1998) Synaptic defects and compensatory regulation of inositol metabolism in inositol polyphosphate 1-phosphatase mutants. Neuron 20:1219-1229.

Ackerman SL, Siegel RW (1986) Chemically reinforced conditioned courtship in Drosophila: responses of wild-type and the dunce, amnesiac and don giovanni mutants. J Neurogenet 3:111-123.

Alzheimer A (1907) Über eine eigenartige Erkrankung der Hirnrinde. Allg Zschr Psychiatr psych-gerichtl Med 64:146-148.

Amtul Z, Lewis PA, Piper S, Crook R, Baker M, Findlay K, Singleton A, Hogg M, Younkin L, Younkin SG, Hardy J, Hutton M, Boeve BF, Tang-Wai D, Golde TE (2002) A presenilin 1 mutation associated with familial frontotemporal dementia inhibits gamma-secretase cleavage of APP and notch. Neurobiol Dis 9:269-273.

Baki L, Shioi J, Wen P, Shao Z, Schwarzman A, Gama-Sosa M, Neve R, Robakis NK (2004) PS1 activates PI3K thus inhibiting GSK-3 activity and tau overphosphorylation: effects of FAD mutations. EMBO J 23:2586-2596.

Berridge MJ (1993) Inositol trisphosphate and calcium signalling. Nature 361:315-325.

Billings LM, Oddo S, Green KN, McGaugh JL, LaFerla FM (2005) Intraneuronal Abeta causes the onset of early Alzheimer's disease-related cognitive deficits in transgenic mice. Neuron 45:675-688.

Bogdanik L, Mohrmann R, Ramaekers A, Bockaert J, Grau Y, Broadie K, Parmentier ML (2004) The Drosophila metabotropic glutamate receptor DmGluRA regulates activity-dependent synaptic facilitation and fine synaptic morphology. J Neurosci 24:9105-9116.

Bolduc FV, Bell K, Cox H, Broadie KS, Tully T (2008) Excess protein synthesis in Drosophila fragile X mutants impairs long-term memory. Nat Neurosci 11:1143-1145.

Boulianne GL, Livne-Bar I, Humphreys JM, Liang Y, Lin C, Rogaev E, St George-Hyslop P (1997) Cloning and characterization of the Drosophila presenilin homologue. Neuroreport 8:1025-1029.

Bullock BP, Habener JF (1998) Phosphorylation of the cAMP response element binding protein CREB by cAMP-dependent protein kinase A and glycogen synthase kinase-3 alters DNA-binding affinity, conformation, and increases net charge. Biochemistry 37:3795-3809.

Caccamo A, Oddo S, Tran LX, LaFerla FM (2007) Lithium reduces tau phosphorylation but not A beta or working memory deficits in a transgenic model with both plaques and tangles. Am J Pathol 170:1669-1675.

Cheung KH, Shineman D, Müller M, Cárdenas C, Mei L, Yang J, Tomita T, Iwatsubo T, Lee VM, Foskett JK (2008) Mechanism of $\mathrm{Ca}^{2+}$ disruption in Alzheimer's disease by presenilin regulation of InsP3 receptor channel gating. Neuron 58:871-883.
Coleman PD, Yao PJ (2003) Synaptic slaughter in Alzheimer's disease. Neurobiol Aging 24:1023-1027.

Crowther DC, Kinghorn KJ, Miranda E, Page R, Curry JA, Duthie FA, Gubb DC, Lomas DA (2005) Intraneuronal Abeta, non-amyloid aggregates and neurodegeneration in a Drosophila model of Alzheimer's disease. Neuroscience 132:123-135.

Davies CA, Mann DM, Sumpter PQ, Yates PO (1987) A quantitative morphometric analysis of the neuronal and synaptic content of the frontal and temporal cortex in patients with Alzheimer's disease. J Neurol Sci 78: 151-164.

DeKosky ST, Scheff SW (1990) Synapse loss in frontal cortex biopsies in Alzheimer's disease: correlation with cognitive severity. Ann Neurol 27:457-464.

Dermaut B, Kumar-Singh S, Engelborghs S, Theuns J, Rademakers R, Saerens J, Pickut BA, Peeters K, van den Broeck M, Vennekens K, Claes S, Cruts M, Cras P, Martin JJ, Van Broeckhoven C, De Deyn PP (2004) A novel presenilin 1 mutation associated with Pick's disease but not beta-amyloid plaques. Ann Neurol 55:617-626.

Deshpande M, Venkatesh K, Rodrigues V, Hasan G (2000) The inositol 1,4,5-trisphosphate receptor is required for maintenance of olfactory adaptation in Drosophila antennae. J Neurobiol 43:282-288.

De Strooper B (2003) Aph-1, Pen-2, and Nicastrin with Presenilin generate an active gamma-Secretase complex. Neuron 38:9-12.

De Strooper B (2007) Loss-of-function presenilin mutations in Alzheimer disease. Talking point on the role of presenilin mutations in Alzheimer disease. ЕMBO Rep 8:141-146.

Dölen G, Osterweil E, Rao BS, Smith GB, Auerbach BD, Chattarji S, Bear MF (2007) Correction of fragile X syndrome in mice. Neuron 56:955-962.

Ejima A, Smith BP, Lucas C, Levine JD, Griffith LC (2005) Sequential learning of pheromonal cues modulates memory consolidation in trainerspecific associative courtship conditioning. Curr Biol 15:194-206.

Ejima A, Smith BP, Lucas C, van der Goes van Naters W, Miller CJ, Carlson JR, Levine JD, Griffith LC (2007) Generalization of courtship learning in Drosophila is mediated by cis-vaccenyl acetate. Curr Biol 17:599-605.

Etcheberrigaray R, Hirashima N, Nee L, Prince J, Govoni S, Racchi M, Tanzi RE, Alkon DL (1998) Calcium responses in fibroblasts from asymptomatic members of Alzheimer's disease families. Neurobiol Dis 5:37-45.

Gong B, Vitolo OV, Trinchese F, Liu S, Shelanski M, Arancio O (2004) Persistent improvement in synaptic and cognitive functions in an Alzheimer mouse model after rolipram treatment. J Clin Invest 114:1624-1634.

Gould TD, Manji HK (2005) Glycogen synthase kinase-3: a putative molecular target for lithium mimetic drugs. Neuropsychopharmacology 30:1223-1237.

Grimes CA, Jope RS (2001) CREB DNA binding activity is inhibited by glycogen synthase kinase- 3 beta and facilitated by lithium. J Neurochem 78:1219-1232.

Hall JC (1994) The mating of a fly. Science 264:1702-1714.

Halliday GM, Song YJ, Lepar G, Brooks WS, Kwok JB, Kersaitis C, Gregory G, Shepherd CE, Rahimi F, Schofield PR, Kril JJ (2005) Pick bodies in a family with presenilin-1 Alzheimer's disease. Ann Neurol 57:139-143.

Hansen TO, Rehfeld JF, Nielsen FC (2004) GSK-3beta reduces cAMPinduced cholecystokinin gene expression by inhibiting CREB binding. Neuroreport 15:841-845.

Hardy J (2006) A hundred years of Alzheimer's disease research. Neuron 52:3-13.

Hardy J (2007) Putting presenilins centre stage. Introduction to the Talking point on the role of presenilin mutations in Alzheimer disease. EMBO Rep 8:134-135.

Hériché JK, Ang D, Bier E, O’Farrell PH (2003) Involvement of an SCFSlmb complex in timely elimination of E2F upon initiation of DNA replication in Drosophila. BMC Genet 4:9.

Hirashima N, Etcheberrigaray R, Bergamaschi S, Racchi M, Battaini F, Binetti G, Govoni S, Alkon DL (1996) Calcium responses in human fibroblasts: a diagnostic molecular profile for Alzheimer's disease. Neurobiol Aging 17:549-555.

Hong CS, Koo EH (1997) Isolation and characterization of Drosophila presenilin homolog. Neuroreport 8:665-668.

Hu Y, Fortini ME (2003) Different cofactor activities in gamma-secretase assembly: evidence for a nicastrin-Aph-1 subcomplex. J Cell Biol 161:685-690.

Huang HC, Klein PS (2006) Multiple roles for glycogen synthase kinase-3 as a drug target in Alzheimer's disease. Curr Drug Targets 7:1389-1397. 
Huang HM, Toral-Barza L, Thaler H, Tofel-Grehl B, Gibson GE (1991) Inositol phosphates and intracellular calcium after bradykinin stimulation in fibroblasts from young, normal aged and Alzheimer donors. Neurobiol Aging 12:469-473.

Huang LQ, Rowan MJ, Anwyl R (1997) mGluR II agonist inhibition of LTP induction, and mGluR II antagonist inhibition of LTD induction, in the dentate gyrus in vitro. Neuroreport 8:687-693.

Huang L, Killbride J, Rowan MJ, Anwyl R (1999a) Activation of mGluRII induces LTD via activation of protein kinase $A$ and protein kinase $C$ in the dentate gyrus of the hippocampus in vitro. Neuropharmacology 38:73-83.

Huang LQ, Rowan MJ, Anwyl R (1999b) Role of protein kinases A and C in the induction of mGluR-dependent long-term depression in the medial perforant path of the rat dentate gyrus in vitro. Neurosci Lett 274:71-74.

Huber KM, Gallagher SM, Warren ST, Bear MF (2002) Altered synaptic plasticity in a mouse model of fragile X mental retardation. Proc Natl Acad Sci U S A 99:7746-7750.

Iijima K, Liu HP, Chiang AS, Hearn SA, Konsolaki M, Zhong Y (2004) Dissecting the pathological effects of human Abeta40 and Abeta42 in Drosophila: a potential model for Alzheimer's disease. Proc Natl Acad Sci U S A 101:6623-6628.

Isoo N, Sato C, Miyashita H, Shinohara M, Takasugi N, Morohashi Y, Tsuji S, Tomita T, Iwatsubo T (2007) Abeta42 overproduction associated with structural changes in the catalytic pore of gamma-secretase: common effects of Pen-2 N-terminal elongation and fenofibrate. J Biol Chem 282:12388-12396.

Ito E, Oka K, Etcheberrigaray R, Nelson TJ, McPhie DL, Tofel-Grehl B, Gibson GE, Alkon DL (1994) Internal $\mathrm{Ca}^{2+}$ mobilization is altered in fibroblasts from patients with Alzheimer disease. Proc Natl Acad Sci U S A 91:534-538.

Joiner MA, Griffith LC (1997) CaM kinase II and visual input modulate memory formation in the neuronal circuit controlling courtship conditioning. J Neurosci 17:9384-9391.

Joiner MA, Griffith LC (1999) Mapping of the anatomical circuit of CaM kinase-dependent courtship conditioning in Drosophila. Learn Mem 6:177-192.

Jope RS, Roh MS (2006) Glycogen synthase kinase-3 (GSK3) in psychiatric diseases and therapeutic interventions. Curr Drug Targets 7:1421-1434.

Kane NS, Robichon A, Dickinson JA, Greenspan RJ (1997) Learning without performance in PKC-deficient Drosophila. Neuron 18:307-314.

Klein PS, Melton DA (1996) A molecular mechanism for the effect of lithium on development. Proc Natl Acad Sci U S A 93:8455-8459.

Kreibich TA, Chalasani SH, Raper JA (2004) The neurotransmitter glutamate reduces axonal responsiveness to multiple repellents through the activation of metabotropic glutamate receptor 1. J Neurosci 24:7085-7095.

Kumar-Singh S, Theuns J, Van Broeck B, Pirici D, Vennekens K, Corsmit E, Cruts M, Dermaut B, Wang R, Van Broeckhoven C (2006) Mean ageof-onset of familial alzheimer disease caused by presenilin mutations correlates with both increased Abeta42 and decreased Abeta40. Hum Mutat 27:686-695.

Mai L, Jope RS, Li X (2002) BDNF-mediated signal transduction is modulated by GSK3beta and mood stabilizing agents. J Neurochem 82:75-83.

Malherbe P, Kratochwil N, Zenner MT, Piussi J, Diener C, Kratzeisen C, Fischer C, Porter RH (2003) Mutational analysis and molecular modeling of the binding pocket of the metabotropic glutamate 5 receptor negative modulator 2-methyl-6-(phenylethynyl)-pyridine. Mol Pharmacol 64:823-832.

Malm TM, Iivonen H, Goldsteins G, Keksa-Goldsteine V, Ahtoniemi T, Kanninen K, Salminen A, Auriola S, Van Groen T, Tanila H, Koistinaho J (2007) Pyrrolidine dithiocarbamate activates Akt and improves spatial learning in APP/PS1 mice without affecting $\beta$-amyloid burden. J Neurosci 27:3712-3721.

Mattson MP (2004) Pathways towards and away from Alzheimer's disease. Nature 430:631-639.

McBride SM, Giuliani G, Choi C, Krause P, Correale D, Watson K, Baker G, Siwicki KK (1999) Mushroom body ablation impairs short-term memory and long-term memory of courtship conditioning in Drosophila melanogaster. Neuron 24:967-977.

McBride SM, Choi CH, Wang Y, Liebelt D, Braunstein E, Ferreiro D, Sehgal A, Siwicki KK, Dockendorff TC, Nguyen HT, McDonald TV, Jongens TA (2005) Pharmacological rescue of synaptic plasticity, courtship behavior, and mushroom body defects in a Drosophila model of fragile X syndrome. Neuron 45:753-764.

Mershin A, Pavlopoulos E, Fitch O, Braden BC, Nanopoulos DV, Skoulakis EM (2004) Learning and memory deficits upon TAU accumulation in Drosophila mushroom body neurons. Learn Mem 11:277-287.

Moehlmann T, Winkler E, Xia X, Edbauer D, Murrell J, Capell A, Kaether C, Zheng H, Ghetti B, Haass C, Steiner H (2002) Presenilin-1 mutations of leucine 166 equally affect the generation of the Notch and APP intracellular domains independent of their effect on Abeta 42 production. Proc Natl Acad Sci U S A 99:8025-8030.

Oddo S, Caccamo A, Shepherd JD, Murphy MP, Golde TE, Kayed R, Metherate R, Mattson MP, Akbari Y, LaFerla FM (2003) Triple-transgenic model of Alzheimer's disease with plaques and tangles: intracellular Abeta and synaptic dysfunction. Neuron 39:409-421.

Otani S, Auclair N, Desce JM, Roisin MP, Crépel F (1999) Dopamine receptors and groups I and II mGluRs cooperate for long-term depression induction in rat prefrontal cortex through converging postsynaptic activation of MAP kinases. J Neurosci 19:9788-9802.

Otani S, Daniel H, Takita M, Crépel F (2002) Long-term depression induced by postsynaptic group II metabotropic glutamate receptors linked to phospholipase $\mathrm{C}$ and intracellular calcium rises in rat prefrontal cortex. J Neurosci 22:3434-3444.

Pagano A, Ruegg D, Litschig S, Stoehr N, Stierlin C, Heinrich M, Floersheim P, Prezèau L, Carroll F, Pin JP, Cambria A, Vranesic I, Flor PJ, Gasparini F, Kuhn R (2000) Thenon-competitive antagonists2-methyl-6-(phenylethynyl)pyridine and 7-hydroxyiminocyclopropan[b]chromen-1a-carboxylic acid ethyl ester interact with overlapping binding pockets in the transmembrane region of group I metabotropic glutamate receptors. J Biol Chem 275:33750-33758.

Palladino MJ, Keegan LP, O'Connell MA, Reenan RA (2000) A-to-I premRNA editing in Drosophila is primarily involved in adult nervous system function and integrity. Cell 102:437-449.

Palop JJ, Jones B, Kekonius L, Chin J, Yu GQ, Raber J, Masliah E, Mucke L (2003) Neuronal depletion of calcium-dependent proteins in the dentate gyrus is tightly linked to Alzheimer's disease-related cognitive deficits. Proc Natl Acad Sci U S A 100:9572-9577.

Pan L, Broadie KS (2007) Drosophila fragile X mental retardation protein and metabotropic glutamate receptor A convergently regulate the synaptic ratio of ionotropic glutamate receptor subclasses. J Neurosci 27:12378 12389.

Pan L, Woodruff E 3rd, Liang P, Broadie K (2008) Mechanistic relationships between Drosophila fragile X mental retardation protein and metabotropic glutamate receptor A signaling. Mol Cell Neurosci 37:747-760.

Parmentier ML, Pin JP, Bockaert J, Grau Y (1996) Cloning and functional expression of a Drosophila metabotropic glutamate receptor expressed in the embryonic CNS. J Neurosci 16:6687-6694.

Peterson C, Ratan RR, Shelanski ML, Goldman JE (1988) Altered response of fibroblasts from aged and Alzheimer donors to drugs that elevate cytosolic free calcium. Neurobiol Aging 9:261-266.

Qi-Takahara Y, Morishima-Kawashima M, Tanimura Y, Dolios G, Hirotani N, Horikoshi Y, Kametani F, Maeda M, Saido TC, Wang R, Ihara Y (2005) Longer forms of amyloid $\beta$ protein: implications for the mechanism of intramembrane cleavage by $\gamma$-secretase. J Neurosci 25:436-445.

Raux G, Gantier R, Martin C, Pothin Y, Brice A, Frebourg T, Campion D (2000) A novel presenilin 1 missense mutation (L153V) segregating with early-onset autosomal dominant Alzheimer's disease. Hum Mutat 16:95.

Sambamurti K, Suram A, Venugopal C, Prakasam A, Zhou Y, Lahiri DK, Greig NH (2006) A partial failure of membrane protein turnover may cause Alzheimer's disease: a new hypothesis. Curr Alzheimer Res 3:81-90.

Saura CA, Choi SY, Beglopoulos V, Malkani S, Zhang D, Shankaranarayana Rao BS, Chattarji S, Kelleher RJ 3rd, Kandel ER, Duff K, Kirkwood A, Shen J (2004) Loss of presenilin function causes impairments of memory and synaptic plasticity followed by age-dependent neurodegeneration. Neuron 42:23-36.

Schroeter EH, Ilagan MX, Brunkan AL, Hecimovic S, Li YM, Xu M, Lewis HD, Saxena MT, De Strooper B, Coonrod A, Tomita T, Iwatsubo T, Moore CL, Goate A, Wolfe MS, Shearman M, Kopan R (2003) A presenilin dimer at the core of the gamma-secretase enzyme: insights from parallel analysis of Notch 1 and APP proteolysis. Proc Natl Acad Sci U S A 100:13075-13080.

Selkoe DJ (2002) Alzheimer's disease is a synaptic failure. Science 298:789-791. 
Serban G, Kouchi Z, Baki L, Georgakopoulos A, Litterst CM, Shioi J, Robakis NK (2005) Cadherins mediate both the association between PS1 and beta-catenin and the effects of PS1 on beta-catenin stability. J Biol Chem 280:36007-36012.

Shen J, Kelleher RJ 3rd (2007) The presenilin hypothesis of Alzheimer's disease: evidence for a loss-of-function pathogenic mechanism. Proc Natl Acad Sci U S A 104:403-409.

Shioi J, Georgakopoulos A, Mehta P, Kouchi Z, Litterst CM, Baki L, Robakis NK (2007) FAD mutants unable to increase neurotoxic Abeta 42 suggest that mutation effects on neurodegeneration may be independent of effects on Abeta. J Neurochem 101:674-681.

Siegel RW, Hall JC (1979) Conditioned responses in courtship behavior of normal and mutant Drosophila. Proc Natl Acad Sci U S A 76:3430-3434.

Siwicki KK, Riccio P, Ladewski L, Marcillac F, Dartevelle L, Cross SA, Ferveur JF (2005) The role of cuticular pheromones in courtship conditioning of Drosophila males. Learn Mem 12:636-645.

Skoulakis EM, Grammenoudi S (2006) Dunces and da Vincis: the genetics of learning and memory in Drosophila. Cell Mol Life Sci 63:975-988.

Small SA, Gandy S (2006) Sorting through the cell biology of Alzheimer's disease: intracellular pathways to pathogenesis. Neuron 52:15-31.

Struhl G, Greenwald I (1999) Presenilin is required for activity and nuclear access of Notch in Drosophila. Nature 398:522-525.

Stutzmann GE, Caccamo A, LaFerla FM, Parker I (2004) Dysregulated IP3 signaling in cortical neurons of knock-in mice expressing an Alzheimer'slinked mutation in presenilin 1 results in exaggerated $\mathrm{Ca}^{2+}$ signals and altered membrane excitability. J Neurosci 24:508-513.

Takasugi N, Tomita T, Hayashi I, Tsuruoka M, Niimura M, Takahashi Y, Thinakaran G, Iwatsubo T (2003) The role of presenilin cofactors in the gamma-secretase complex. Nature 422:438-441.

Takei K, Shin RM, Inoue T, Kato K, Mikoshiba K (1998) Regulation of nerve growth mediated by inositol 1,4,5-trisphosphate receptors in growth cones. Science 282:1705-1708.

Tanji C, Yamamoto H, Yorioka N, Kohno N, Kikuchi K, Kikuchi A (2002) A-kinase anchoring protein AKAP220 binds to glycogen synthase kinase3beta (GSK-3beta) and mediates protein kinase A-dependent inhibition of GSK-3beta. J Biol Chem 277:36955-36961.

Tatebayashi Y, Takeda M, Kashiwagi Y, Okochi M, Kurumadani T, Sekiyama A, Kanayama G, Hariguchi S, Nishimura T (1995) Cell-cycle-dependent abnormal calcium response in fibroblasts from patients with familial Alzheimer's disease. Dementia 6:9-16.
Terry RD, Masliah E, Salmon DP, Butters N, DeTeresa R, Hill R, Hansen LA Katzman R (1991) Physical basis of cognitive alterations in Alzheimer's disease: synapse loss is the major correlate of cognitive impairment. Ann Neurol 30:572-580.

Tompkins L, Siegel RW, Gailey DA, Hall JC (1983) Conditioned courtship in Drosophila and its mediation by association of chemical cues. Behav Genet 13:565-578.

Venkatesh K, Hasan G (1997) Disruption of the IP3 receptor gene of Drosophila affects larval metamorphosis and ecdysone release. Curr Biol 7:500-509.

Walker ES, Martinez M, Brunkan AL, Goate A (2005) Presenilin 2 familial Alzheimer's disease mutations result in partial loss of function and dramatic changes in Abeta 42/40 ratios. J Neurochem 92:294-301.

Walsh DM, Selkoe DJ (2004) Deciphering the molecular basis of memory failure in Alzheimer's disease. Neuron 44:181-193.

Westphalen RI, Scott HL, Dodd PR (2003) Synaptic vesicle transport and synaptic membrane transporter sites in excitatory amino acid nerve terminals in Alzheimer disease. J Neural Transm 110:1013-1027.

Williams RS, Cheng L, Mudge AW, Harwood AJ (2002) A common mechanism of action for three mood-stabilizing drugs. Nature 417:292-295.

Wittmann CW, Wszolek MF, Shulman JM, Salvaterra PM, Lewis J, Hutton M, Feany MB (2001) Tauopathy in Drosophila: neurodegeneration without neurofibrillary tangles. Science 293:711-714.

Wolfe MS (2007) When loss is gain: reduced presenilin proteolytic function leads to increased Abeta42/Abeta40. Talking point on the role of presenilin mutations in Alzheimer disease. EMBO Rep 8:136-140.

Yan QJ, Rammal M, Tranfaglia M, Bauchwitz RP (2005) Suppression of two major Fragile X Syndrome mouse model phenotypes by the mGluR5 antagonist MPEP. Neuropharmacology 49:1053-1066.

Yao PJ, Zhu M, Pyun EI, Brooks AI, Therianos S, Meyers VE, Coleman PD (2003) Defects in expression of genes related to synaptic vesicle trafficking in frontal cortex of Alzheimer's disease. Neurobiol Dis 12:97-109.

Ye Y, Fortini ME (1998) Characterization of Drosophila Presenilin and its colocalization with Notch during development. Mech Dev 79:199-211.

Ye Y, Fortini ME (1999) Apoptotic activities of wild-type and Alzheimer's disease-related mutant presenilins in Drosophila melanogaster. J Cell Biol 146:1351-1364.

Ye Y, Lukinova N, Fortini ME (1999) Neurogenic phenotypes and altered Notch processing in Drosophila Presenilin mutants. Nature 398:525-529. 